University of Nebraska - Lincoln

DigitalCommons@University of Nebraska - Lincoln

\title{
Effect of Long Chains on the Threshold Stresses for Flow-Induced Crystallization in iPP: Shish Kebabs vs. Sausages
}

\author{
Lucia Fernandez-Ballester \\ University of Nebraska-Lincoln, lucia.fernandez@unl.edu \\ Derek W. Thurman \\ ExxonMobil Chemical Co., Baytown, TX \\ Weijun Zhou \\ Dow Chemical Company, Freeport, TX \\ Julia A. Kornfield \\ California Institute of Technology, jak@cheme.caltech.edu
}

Follow this and additional works at: https://digitalcommons.unl.edu/mechengfacpub

Part of the Mechanical Engineering Commons

Fernandez-Ballester, Lucia; Thurman, Derek W.; Zhou, Weijun; and Kornfield, Julia A., "Effect of Long Chains on the Threshold Stresses for Flow-Induced Crystallization in iPP: Shish Kebabs vs. Sausages" (2012). Mechanical \& Materials Engineering Faculty Publications. 68.

https://digitalcommons.unl.edu/mechengfacpub/68

This Article is brought to you for free and open access by the Mechanical \& Materials Engineering, Department of at DigitalCommons@University of Nebraska - Lincoln. It has been accepted for inclusion in Mechanical \& Materials Engineering Faculty Publications by an authorized administrator of DigitalCommons@University of Nebraska Lincoln. 


\title{
Effect of Long Chains on the Threshold Stresses for Flow-Induced Crystallization in iPP: Shish Kebabs vs. Sausages
}

\author{
Lucia Fernandez-Ballester, ${ }^{1}$ Derek W. Thurman, ${ }^{2}$ Weijun Zhou, ${ }^{3}$ and Julia A. Kornfield ${ }^{4}$
}

1. Department of Mechanical and Materials Engineering, University of Nebraska at Lincoln, Lincoln, Nebraska 68588, USA

2. Baytown Technology and Engineering Complex, ExxonMobil Chemical Co., 5200 Bayway Dr., Baytown, Texas 77520, USA

3. Core R\&D - Materials Science \& Engineering, The Dow Chemical Company, 2301 N. Brazosport Blvd., B-1470, Freeport, Texas 77541, USA

4. Division of Chemistry and Chemical Engineering, California Institute of Technology, Pasadena, California 91125, USA

\section{Abstract}

The addition of small concentrations ( $2 \mathrm{wt} \%$ or less) of ultrahigh molecular weight isotactic polypropylene $\left(M_{\mathrm{L}} \sim 3500 \mathrm{~kg} / \mathrm{mol}\right)$ to a matrix of lower molecular weight chains $\left(M_{\mathrm{S}} \sim 186 \mathrm{~kg} / \mathrm{mol}\right.$, e.g. $\left.M_{\mathrm{L}} / M_{\mathrm{S}} \sim 20\right)$ substantially decreases the critical stress for inducing a highly oriented skin under flow-induced crystallization conditions-significantly more than for blends of $M_{\mathrm{L}} / M_{\mathrm{S}} \sim 5$ (Seki et al.) - and promotes the formation of point precursors and oriented "sausage-like" structures not observed for $M_{\mathrm{L}} / M_{\mathrm{S}} \sim 5$. These differences correlate with the onset of long chain stretching during shear: the ratio of long chains' Rouse time to short chains' disengagement time indicates that $3500 \mathrm{~kg} / \mathrm{mol}$ chains can easily stretch if tethered onto a point nuclei and even when untethered. Adding $3500 \mathrm{~kg} / \mathrm{mol}$ chains has strong effects that saturate beyond the overlap concentration, suggesting that an uninterrupted supply of long chains greatly accelerates formation of threads. A conceptual model is proposed that distinguishes between a critical stress for shish initiation and that for propagation.

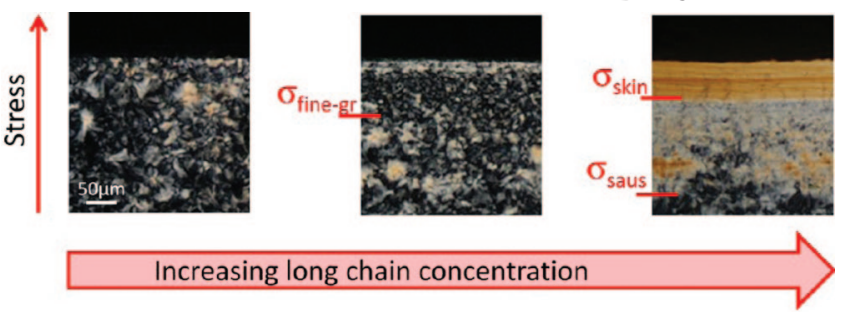

\section{Introduction}

Renewed interest in flow-induced crystallization (FIC) of polymers has been fueled by a combination of innovative experimental methods, ${ }^{[1-7]}$ advances in control of molecular variables, ${ }^{[8-12]}$ and discoveries that challenge long-standing concepts. ${ }^{[13-16]}$ Technologically, processing flows can greatly accelerate the kinetics of crystallization and induce the formation of highly oriented solid-state morphologies that have very different properties from quiescently crystallized material of identical molecular composition: the highly oriented morphology confers greater density, modulus, and hardness and lower permeability and thermal expansion coefficient. ${ }^{17-}$ 24] The different crystallization environments in a flow field can produce a "skin-core" morphology that has dense, oriented crystalline layers and an isotropic crystalline core, with a relatively sharp boundary between them. ${ }^{[1,20,21,25]}$ Thus, the effects of flow are so highly nonlinear that there seem to be "thresholds" that, once crossed, lead to qualitatively different behavior. An array of controlling variables have been proposed over the years, i.e., melt entropy, shear stress, shear rate, strain, and specific work. $\left.{ }^{[4,} 6,23,25-29\right]$ However, it is not yet known how to best define such thresholds or how they depend on the molecular attributes of the polymer.

Phenomenologically, for a given material, there is evidence of a threshold stress $\sigma_{\mathrm{pt}}$ above which shear flow can induce the formation of "point-like" nuclei ${ }^{\mathrm{a}}$ and below which shearing has negligible effect. Another critical shear stress $\sigma_{\text {skin }}>\sigma_{\mathrm{pt}}$ is associated with the ability of shear to induce prolific formation of oriented "thread-like" precursors, also known as "shish". Thread-like precursors provide nucleating surfaces from which oriented lamellae-also known as "kebabs" - grow radially. When the separation between shish is so small that cyllindrulites impinge prior to significant noncrystallographic branching a highly oriented morphology results, known as the "highly oriented skin". There is evidence that the presence of point nuclei is a prerequisite for prolific formation of shish, ${ }^{[1,28,31,32]}$ but the exact nature and mechanisms of formation of both point-like and threadlike precursors remains the subject of debate. Proposed mechanisms of formation of shish include propagation upstream and downstream from already present point-like precursor $^{[1]}$ the aggregation or accumulation of point-like nuclei, ${ }^{[28]}$ and stretching of segments of chains tethered by junctions in an entangled physical network. ${ }^{[33,34]}$

To gain further insight into the formation of thread-like precursors (a.k.a. shish), this study examines the molecular basis of the effects of "long chains." The longest chains in the melt strongly influence the formation of shish, ${ }^{[13,27,35-42]}$ and it is thought that their ability to undergo significant degrees of orientation or stretch during flow is key to their effects. ${ }^{[43-45]}$ In contrast, the creation of point-like nuclei is insensitive to long chains, suggesting that the average segmental 
orientation dominates this process. ${ }^{[27]}$ Efforts to establish the specific roles of the length and concentration of long chains studying the formation of shish include a number of studies using the bimodal blend approach. ${ }^{[4,13,26,27,33,46-48]}$ The specific design of a model blend determines the type of information that can be extracted regarding the mechanism of formation of flow-induced precursors.

Here, bimodal blends with long chains that are unusually large compared to the matrix chains $\left(M_{\mathrm{L}} / M_{\mathrm{S}} \sim 20\right)$ are used to explore the effect of chain stretching. To draw conclusions regarding the effect of long chain length, the matrix polymer is the same as in our previous study that examined $M_{\mathrm{L}} / M_{\mathrm{S}} \sim$ 5 using long chains of $923 \mathrm{~K} \mathrm{~g} / \mathrm{mol}$ (referred to here as $1 \mathrm{M}$ ). [27] The constituent polymers have fairly narrow distribution, rather than components with broad distributions. ${ }^{[26,33,47,49]}$ Shish in the highly oriented skin are not solely composed of long chains, ${ }^{[14]}$ so we use a matrix polymer that crystallizes as readily as the long chains, rather than acting as a solvent. $[46,47]$ The concentration of long chains is kept low $\left(C_{\mathrm{L}} \leq 2 \mathrm{wt}\right.$ $\%$ ), so all of the blends in the present study and in our prior study with $1 \mathrm{M}$ long chains have nearly matched quiescent crystallization kinetics and morphology; thus, comparisons at a specific temperature represent well-matched subcooling. The small concentrations of long chains also give all the blends viscosity similar to that of the matrix alone (within a factor of 3 ); thus, comparisons made at a specific shear stress for a specific shearing time represent approximately matched rates of deformation, melt entropy, total strain, and specific work. $[4,23,26,28,50$, ${ }^{51]}$ Therefore, the present blends enable us to unambiguously identify effects due to long chains. The results indicate that the onset of chain stretching in the longest chains may govern the formation of oriented thread-like precursors. ${ }^{[45]}$ We propose a conceptual model that is consistent with the observed effects of long chain length and concentration on the processes of initiation and propagation of thread-like precursors.

\section{Experimental Section}

Bimodal blends of isotactic polypropylene (iPP) were prepared with low concentrations (2 wt \% or less) of high molecular weight $\left(M_{\mathrm{w}}=3500 \mathrm{~K} \mathrm{~g} / \mathrm{mol}, M_{\mathrm{w}} / M_{\mathrm{n}}=1.8\right.$, referred to as $3.5 \mathrm{M}$ "long chains") chains in a matrix of shorter, yet still highly entangled chains $\left(M_{\mathrm{w}}=186 \mathrm{~K} \mathrm{~g} / \mathrm{mol}, M_{\mathrm{w}} / M_{\mathrm{n}}=2.3\right.$, “Base-PP"), where $M_{\mathrm{w}}$ and $M_{\mathrm{n}}$ are the weight-average and number-average molecular weights. Both polymers, provided by Dow Chemical Co., were synthesized using metallocene catalysts (Table 1). The "long" polypropylene has somewhat greater stereoregularity $([\mathrm{mmmm}]>98 \%)$ than the short chains $([\mathrm{mmmm}]=96 \%)$.

The "Base-PP" is the same resin used in a previous bimodal blend study by Seki et al. ${ }^{[27]}$ The 3.5M long chains were synthesized as follows: A 2 L stainless steel reactor was charged with triethylaluminum $(1 \mathrm{~mL}, 1 \mathrm{M})$ as a scavenger, purified liquid propylene $(600 \mathrm{~g})$,

Table 1. Molecular Characteristics of the Isotactic Polypropylene Components Used for the Bimodal Blends

\begin{tabular}{lccccc}
\hline & $\begin{array}{c}M_{\mathrm{w}} \\
(\mathrm{kg} / \mathrm{mol})^{\mathrm{a}}\end{array}$ & $\begin{array}{c}M_{\mathrm{n}} \\
(\mathrm{kg} / \mathrm{mol})^{\mathrm{a}}\end{array}$ & $M_{\mathrm{w}} / M_{\mathrm{n}}$ & $\begin{array}{c}{[\mathrm{mmmm}]} \\
(\mathrm{mol} \%)^{\mathrm{b}}\end{array}$ & $T_{\mathrm{m}}\left({ }^{\circ} \mathrm{C}\right)^{\mathrm{c}}$ \\
\hline Base-PP & 186.0 & 86.9 & 2.3 & 96.0 & 149.3 \\
$3.5 \mathrm{M}$ & 3500 & 1950 & 1.8 & $>98$ & 144.3 \\
\hline
\end{tabular}

a. Determined by GPC-MALLS.

b. ${ }^{13} \mathrm{C}$ NMR.

c. The apparent melting temperature was determined as the peak temperature of differential scanning calorimetry (DSC) endotherm on second heating with scanning rate of $5{ }^{\circ} \mathrm{C} / \mathrm{min}$ under a $\mathrm{N}_{2}$ atmosphere. and a metallocene catalyst $(0.105 \mathrm{~g})$. The catalyst was rinsed in hexane $(10 \mathrm{~mL})$ twice and was allowed to prepolymerize at $20^{\circ} \mathrm{C}$ for 10 min. The reactor was then slowly heated to $70^{\circ} \mathrm{C}$ over a period of $\sim 12 \mathrm{~min}$, and the reaction was left to run at $70^{\circ} \mathrm{C}$ and 470 psi pressure for a total of $70 \mathrm{~min}$. The product was flash transferred into a knockout drum and transferred into a vacuum oven for drying.

Because of the vastly different molecular weights of the two iPPs, bidisperse materials were prepared by solution blending, as described previously. ${ }^{[6,27]}$ Briefly, desired amounts of 3.5M "long chains" and Base-PP (Table 2) were dissolved in hot xylene under an inert atmosphere until a homogeneous solution was obtained and then quickly precipitated into cold methanol. The resulting "fluff" was filtered and washed with methanol and then sprayed with a measured amount of an acetone solution of a 1:1 mixture of antioxidants (Irganox 1010 and Irgafos 168) to achieve $2000 \mathrm{ppm}$ to the polypropylene. Finally, the polymer fluff was dried at $80^{\circ} \mathrm{C}$ under vacuum for several days to ensure removal of all remaining solvent. As a control, Base-PP (no 3500K long chains added) was subjected to the same solution blending procedure (B0). Long chain concentrations $C_{\mathrm{L}}$ up to $\sim 5$ times their overlap concentration $\left(C_{\mathrm{L}}{ }^{*}\right)$ were examined (Table 2):

$$
C_{\mathrm{L}}{ }^{*}=\frac{3 M_{\mathrm{w}}}{4 \pi\left(R_{\mathrm{g}}\right)^{3 / 2} N_{\mathrm{a}}}
$$

where $R_{\mathrm{g}}$ is the radius of gyration and $N_{\mathrm{a}}$ is Avogadro's number. Using the literature value of $\left(\left\langle R_{\mathrm{g}}{ }^{2}\right\rangle\right)^{1 / 2} /\left(M_{\mathrm{w}}^{\mathrm{a}}{ }^{1 / 2}\right)=0.39 \AA /(\mathrm{g} / \mathrm{mol})^{1 / 2},[52]$ long chains of $3500 \mathrm{~kg} / \mathrm{mol}$ long chains have $C_{\mathrm{L}}{ }^{*}=0.0036 \mathrm{~g} / \mathrm{cm}^{3}$. The blends were characterized by differential scanning calorimetry (DSC) using a Perkin-Elmer DSC-7 instrument with 6-9 mg of sample under a $\mathrm{N}_{2}$ atmosphere. Peak temperatures during the second heating and cooling cycle between 220 and $50{ }^{\circ} \mathrm{C}$ at a rate of $5{ }^{\circ} \mathrm{C} /$ min are reported as $T_{\mathrm{m}}$ and $T_{x^{\prime}}$ respectively (Table 2).

Flow-induced crystallization experiments were carried out in an apparatus ${ }^{[2]}$ capable of imposing a strong shear pulse on a polymer melt for a precisely controlled time and prescribed thermal conditions. The flow channel consists of a rectangular slit with aspect ratio $>10: 1 .{ }^{[2]}$ The maximum strain that can be applied to the polymer melt is constrained by the geometry of the channel, as described in the Supporting Information of Kumaraswamy et al. ${ }^{[13]}$ We use pressure-driven slit flow because it allows quick imposition and removal of very high wall shear stresses. This experimental configuration has a trade-off in that the stress is not uniform, which must be taken into account when interpreting the depth-averaged observables recorded in real time, i.e., birefringence, turbidity, and wideangle X-ray diffracted intensity. ${ }^{[6]}$ In the velocity gradient direction, the imposed shear stress varies linearly from the value at the wall $\left(\sigma_{w}\right)$ to 0 at the center of the flow channel (Figure 1). The experimental protocol (Figure 2) was as follows: the flow cell was filled with the polymer melt using a low wall shear stress at $215^{\circ} \mathrm{C}$; it was held at this temperature $\left(T_{\text {ercos }}\right)$ for $5 \mathrm{~min}$ to erase any history effects and to fully relax the melt; $[27]$ then the melt was cooled to $T_{x}\left(137^{\circ} \mathrm{C}\right)$, and a brief shear pulse with a specified wall shear stress $\left(\sigma_{\mathrm{w}}\right)$ was imposed for a specific shearing time $\left(t_{\mathrm{s}}\right)$. Subsequently, the progress

Table 2. Characteristics of the Bimodal Blends of 3.5M Long Chains in Base-PP Short Chains ${ }^{a}$

\begin{tabular}{llllll}
\hline & $3.5 \mathrm{M}(\mathrm{wt} \%)$ & $C_{\mathrm{L}}\left(\mathrm{mg} / \mathrm{cm}^{3}\right)$ & $C_{\mathrm{L}} / C_{\mathrm{L}}{ }^{*}$ & $T_{x}\left({ }^{\circ} \mathrm{C}\right)$ & $T_{\mathrm{m}}\left({ }^{\circ} \mathrm{C}\right)$ \\
\hline B0 & 0 & 0 & 0 & 109.9 & 149.6 \\
$0125 \mathrm{p}$ & 0.125 & 1.07 & 0.3 & 111.3 & 151.1 \\
$025 \mathrm{p}$ & 0.25 & 2.14 & 0.6 & 110.9 & 150.2 \\
05p & 0.5 & 4.27 & 1.2 & 110.6 & 150.5 \\
1p & 1 & 8.54 & 2.4 & 110.8 & 149.6 \\
2p & 2 & 17.08 & 4.8 & 110.8 & 149.6 \\
\hline
\end{tabular}

a. $C_{L}$ is the concentration of $3.5 \mathrm{M}$ long chains. $T_{x}$ and $T_{m}$ were determined as the peak temperatures of differential scanning calorimetry (DSC) traces on second cooling and heating, respectively. The scanning rate was $5^{\circ} \mathrm{C} / \mathrm{min}$, and measurements were performed under a $\mathrm{N}_{2}$ atmosphere. 


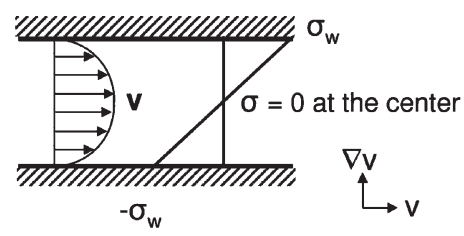

Figure 1. Schematic showing flow profile and shear stress profile across the gap of the rectangular slit channel. The in-situ optical and ex-situ X-ray beam traverse the sample along the velocity gradient direction, denoted $\nabla \mathbf{v}$.

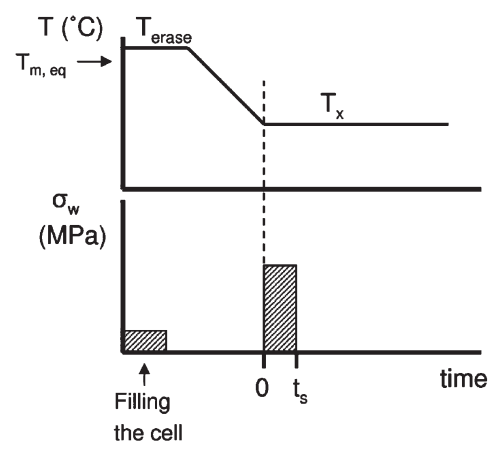

Figure 2. Experimental protocol for flow-induced crystallization experiments.

of isothermal crystallization at $137^{\circ} \mathrm{C}$ was monitored with rheo-optical methods for $75 \mathrm{~min}$; then the flow cell was removed from the apparatus and allowed to cool to room temperature over $\sim 10 \mathrm{~min}$. The sample was then removed for ex-situ characterization. Control experiments under quiescent conditions (in which no shear pulse is imposed) were performed, and two sets of $e x$-situ samples were prepared: one set was cooled after 75 min of isothermal crystallization for comparison with the shear experiments above, and the other set was given $14 \mathrm{~h}$ to crystallize isothermally to visualize the quiescent nucleation density at $137^{\circ} \mathrm{C}$.

Real-time optical measurements probe the optical anisotropy and degree of turbidity of the polymer sample during and after shear, as described elsewhere. ${ }^{[2]}$ The laser beam traverses the flow channel in the velocity gradient direction $\nabla \mathrm{v}$ (Figure 1). The incoming beam is linearly polarized at $45^{\circ}$ with respect to $\mathrm{v}$; the transmitted light is analyzed using a polarizing beamsplitter so that the intensities transmitted through crossed and parallel polarizers are recorded simultaneously $\left(\mathrm{I}_{\perp}\right.$ and $\mathrm{I}_{\|}$, respectively). At early times (when the retardance $\delta<\pi$ ), $\delta$ is computed using Equation 2. At later times $(\delta>\pi)$, the retardance is estimated from the successive maxima (and minima) in the $\mathrm{I}_{\perp} /\left(\mathrm{I}_{\perp}+\mathrm{I}_{\|}\right)$signal, corresponding to integer orders, $n \pi .{ }^{[53]}$ Prior to the onset of significant depolarization due to multiple scattering, $I_{\perp} /\left(I_{\perp}+I_{\|}\right)$can be used to evaluate the retardance:

$$
\frac{I_{\perp}}{I_{\perp}+I_{\|}}=\sin ^{2}\left(\frac{\pi \Delta n d}{\lambda}\right)=\sin ^{2}\left(\frac{\delta}{2}\right)
$$

where $\Delta n$ is the birefringence, $d$ is the length of the optical path through the sample, $\lambda$ is the wavelength of the probing beam, and $\delta$ is the retardance. The turbidity of the sample is monitored by normalizing the total intensity of the beam transmitted through the sample at a given time by the initial intensity that was transmitted through the melt before shear was imposed:

$$
\frac{I_{\text {total }}(t)}{\left(I_{\text {total }}\right)_{0}}=\frac{I_{\perp}+I_{\|}}{\left(I_{\perp}+I_{\|}\right)_{0}}
$$

Ex-situ characterization of the final morphology was performed using polarized optical microscopy (POM) and wide-angle X-ray diffraction (WAXD). Optical micrographs of sections cut in the flowvelocity gradient plane $(\mathbf{v}-\nabla \mathbf{v})$ were recorded through crossed polarizer $(\mathrm{P})$ and analyzer $(\mathrm{A})$ using two orientations of the sample:

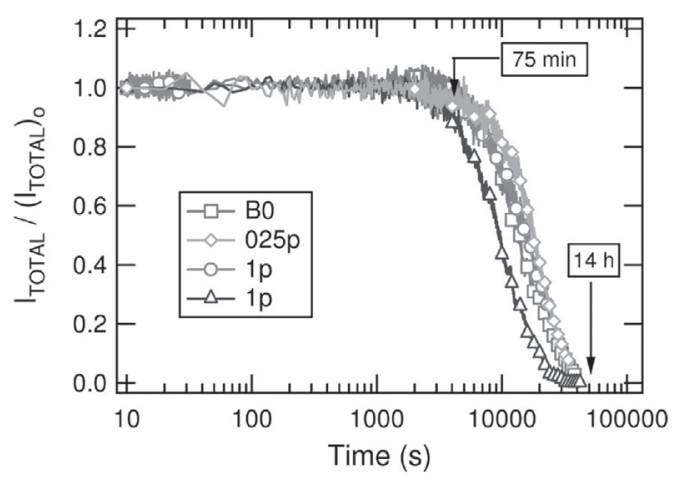

Figure 3. In-situ turbidity measurement during quiescent crystallization at $137{ }^{\circ} \mathrm{C}$ of $\mathrm{B} 0,025 \mathrm{p}$, and $1 \mathrm{p}$. Results for duplicate experiments on $1 p$ are shown (circles and triangles) to illustrate variability due to the small number of nucleation events that occur in the sample volume. Arrows indicate the time points at which samples were cooled to ambient temperature and removed for ex-situ evaluation.

with the flow direction parallel or at $45^{\circ}$ with respect to P. Two-dimensional WAXD patterns of selected quenched samples were recorded with the X-ray beam oriented along the $\nabla \mathbf{v}$ direction (the same direction as the laser beam during real-time rheo-optical measurements). WAXD measurements were performed on the X27C beamline of the U.S. National Synchrotron Light Source (NSLS at Brookhaven National Laboratory, Upton, NY) using X-ray wavelength of $1.371 \AA$ A. Patterns were recorded with a MAR CCD detector placed $17 \mathrm{~cm}$ from the sample. The camera length was calibrated with an $\mathrm{Al}_{2} \mathrm{O}_{3}$ standard. The 2D WAXD patterns were normalized by the beam intensity; the intensity due to background was subtracted. The azimuthal dependence of the scattered intensity was computed for the reflection corresponding to the (110) plane of the a crystal morph of isotactic polypropylene.

\section{Results}

Quiescent Crystallization. The addition of small concentrations (up to $2 \mathrm{wt} \%$ ) of $3.5 \mathrm{M}$ long chains to the base resin Base-PP did not change the kinetics of quiescent crystallization as indicated by DSC measurements under nonisothermal conditions (Table 2) and by turbidity during isothermal quiescent crystallization at $137^{\circ} \mathrm{C}$ (Figure 3). Nor did the added long chains discernibly affect the morphology formed during quiescent, isothermal crystallization at $137^{\circ} \mathrm{C}$ for 14 h (Figure 4, left and middle micrographs). Ex-situ micrographs show a small number of large spherulites (up to 200 $\mu \mathrm{m}$ in diameter) for both $\mathrm{B} 0$ and $1 \mathrm{p}$. The difference between the pair of duplicate $1 p$ experiments shown in Figure 3 illustrates that quiescent crystallization times determined by turbidity can vary up to $50 \%$ due to the small number of nucleation events that occur at $137{ }^{\circ} \mathrm{C}$ in the volume probed by the laser beam. Note that very little turbidity develops during the first $75 \mathrm{~min}$, the time at which sheared specimens are cooled. For comparison to the micrographs of the sheared samples, quiescent experiments were also performed using the same hold time $\left(75 \mathrm{~min}\right.$ at $\left.137^{\circ} \mathrm{C}\right)$ : the resulting quiescent morphology has much smaller spherullites than the case of $14 \mathrm{~h}$ at $T_{x}$ followed by cooling (Figure 4, compare right vs center micrographs).

Effect of $C_{\mathrm{L}}$ on Flow-Induced Morphologies. In contrast to quiescent crystallization, the addition of long chains strongly affects the final morphology obtained when shear is imposed on the subcooled melt. To isolate the effects of $C_{\mathrm{L}}$ specifically, the behavior of the different binary blends are 


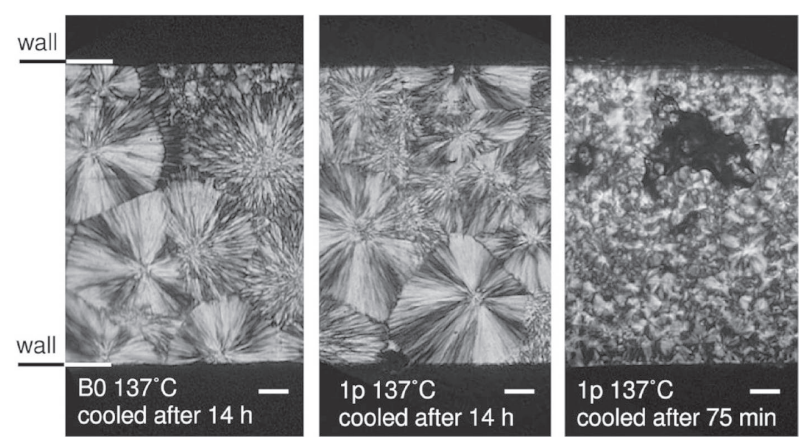

Figure 4. Polarized optical micrographs of the ex-situ morphology after quiescent crystallization at $137{ }^{\circ} \mathrm{C}$ of B0 cooled after $14 \mathrm{~h}$ (left), $1 \mathrm{p}$ cooled after $14 \mathrm{~h}$ (center), and $1 \mathrm{p}$ cooled after $75 \mathrm{~min}$ (right). The $14 \mathrm{~h}$ holding time at $137^{\circ} \mathrm{C}$ was chosen such that spherullites grow to impingement isothermally and nucleation during cooling can be neglected. Nonisothermal nucleation and growth play a major role in determining the morphology when cooling begins after $75 \mathrm{~min}$. Note that there is no evidence of enhanced nucleation at the wall. Scale bars correspond to $50 \mu \mathrm{m}$.
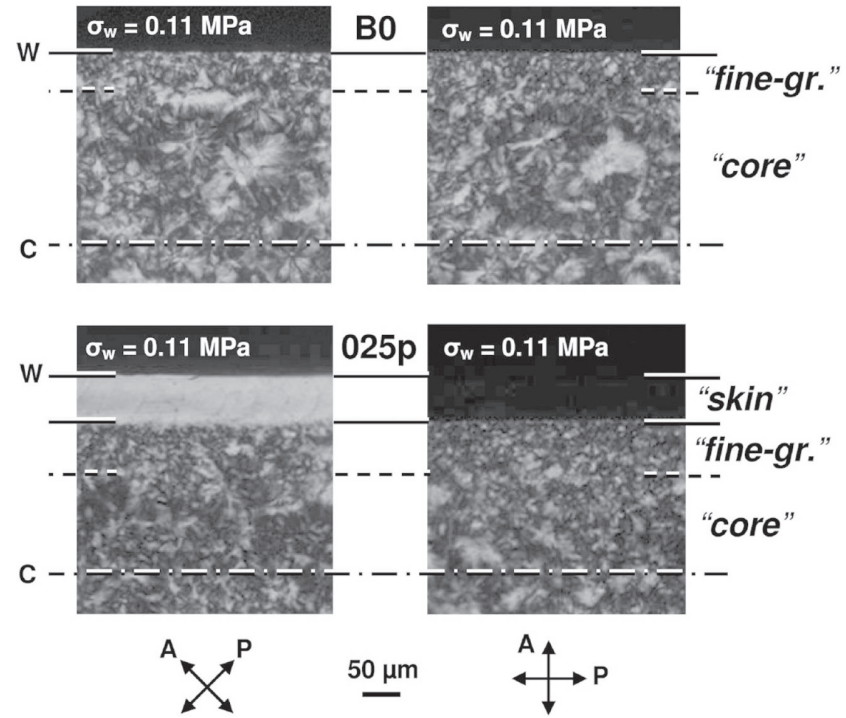

Figure 5. Ex-situ polarized optical micrographs for B0 (top) and $025 \mathrm{p}$ (bottom) crystallized at $137^{\circ} \mathrm{C}$ for $75 \mathrm{~min}$ after imposing a pulse of $\sigma_{\mathrm{w}}$ $=0.11 \mathrm{MPa}$, then cooled, removed, and sectioned. To impose similar total shear strain at the wall, shearing times were chosen to give matched extruded amounts of $\sim 100 \mathrm{mg}\left(t_{\mathrm{s}}=1.4\right.$ and $2.4 \mathrm{~s}$ for B0 and $025 p$, respectively). Flow direction is horizontal. Left column: polarizer $\mathrm{P}$ is $45^{\circ}$ to flow; right column: $\mathrm{P}$ is parallel to flow. The distance between the center (C) and the wall (W) is $250 \mu \mathrm{m}$. The lines at the margin of the figures indicate the threshold stresses for flow-induced formation of (solid line) a highly oriented skin and (dashed line) a fine grained layer (values shown in Figure 8).

compared at a fixed $T_{x}=137{ }^{\circ} \mathrm{C}$, total mass extruded $(\sim 100$ $\mathrm{mg}$ ), and isothermal hold time (75 min) prior to cooling to ambient temperature for specific choices of the wall shear stress $\sigma_{\mathrm{w}}$.

The base resin B0 did not form a highly oriented skin even for the high wall shear stress of $\sigma_{\mathrm{w}}=0.11 \mathrm{MPa}$ (Figure 5 top), while the addition of $0.25 \mathrm{wt} \%$ of $3.5 \mathrm{M}$ chains was sufficient to enable formation of oriented precursors (highly oriented skin for 025p in Figure 5, bottom). However, both B0 and $025 p$ exhibited a fine-grained layer-a macroscopically isotropic region with smaller structures - and a spherullitic
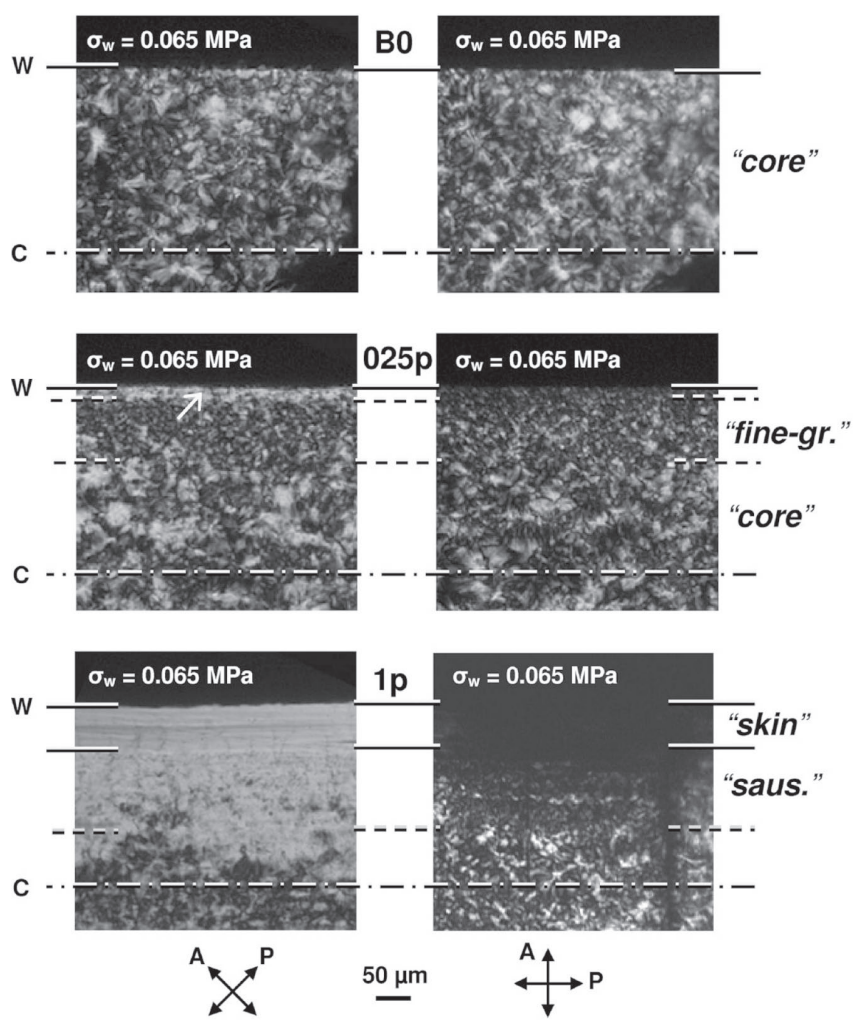

Figure 6. Ex-situ polarized optical micrographs of B0 (top), $0.25 \mathrm{p}$ (middle), and $1 \mathrm{p}$ (bottom) sheared at $137^{\circ} \mathrm{C}$ with wall shear stress $\sigma_{\mathrm{w}}$ $=0.065 \mathrm{MPa}$ and cooled after $75 \mathrm{~min}$. The arrow (middle, left) points to a structure that appears bright for polarizer $P$ and analyzer $A$ at $\pm 45^{\circ}$ with respect to the flow direction and dark when $P$ and $A$ are parallel and orthogonal to the flow direction. The extruded amounts were $\sim 100$ $\mathrm{mg}\left(t_{\mathrm{s}}=8.3,8.7\right.$, and $12 \mathrm{~s}$ for $\mathrm{B} 0,025 \mathrm{p}$, and $1 \mathrm{p}$, respectively).

core, with the fine-grained layer extending a greater distance from the wall in $025 p$ than for B0.

When the wall shear stress is reduced to an intermediate level, $\sigma_{\mathrm{w}}=0.065 \mathrm{MPa}$, the sample with $C_{\mathrm{L}}=0.25 \mathrm{wt} \%(025 \mathrm{p}$, Figure 6 middle) only develops a very thin irregular layer having a few oriented structures near the wall that appear bright when $\mathrm{P} / \mathrm{A}$ are at $\pm 45^{\circ}$ to flow (left). In contrast, the blend with $C_{\mathrm{L}}=1 \mathrm{wt} \%(1 \mathrm{p})$ develops a highly oriented skin that is $\sim 60 \mu \mathrm{m}$ thick (Figure 6, bottom), has a narrow spherulitic core region near the center of the channel, and has an irregular, birefringent region from approximately 60 to 160 $\mu \mathrm{m}$ from the wall with many oriented "sausage-like" structures (shish-kebab structures in which the oriented lamellae have grown to great distances from the central thread), called the "sausage layer." The highly oriented skin is much more birefringent and uniform than the "sausage" layer. This distinction is easily observed when $\mathrm{P}$ is placed along the flow direction (right image): the skin area is completely dark, while the sausage morphology shows bright and dark striated structures. Note that neither B0 nor 025p exhibits a region significantly populated with sausage-like structures.

Increasing $C_{\mathrm{L}}$ further enabled oriented morphologies to form at progressively reduced shear stress: while $\sigma_{\mathrm{w}}=0.065$ MPa was sufficient to induce a highly oriented skin for $C_{\mathrm{L}}$ $=1 \mathrm{wt} \%$ (but not for $0.25 \mathrm{wt} \%$ ), Figure 6, a lower $\sigma_{\mathrm{w}}=0.037$ $\mathrm{MPa}$ induced both a sausage layer and a thick, highly ori- 


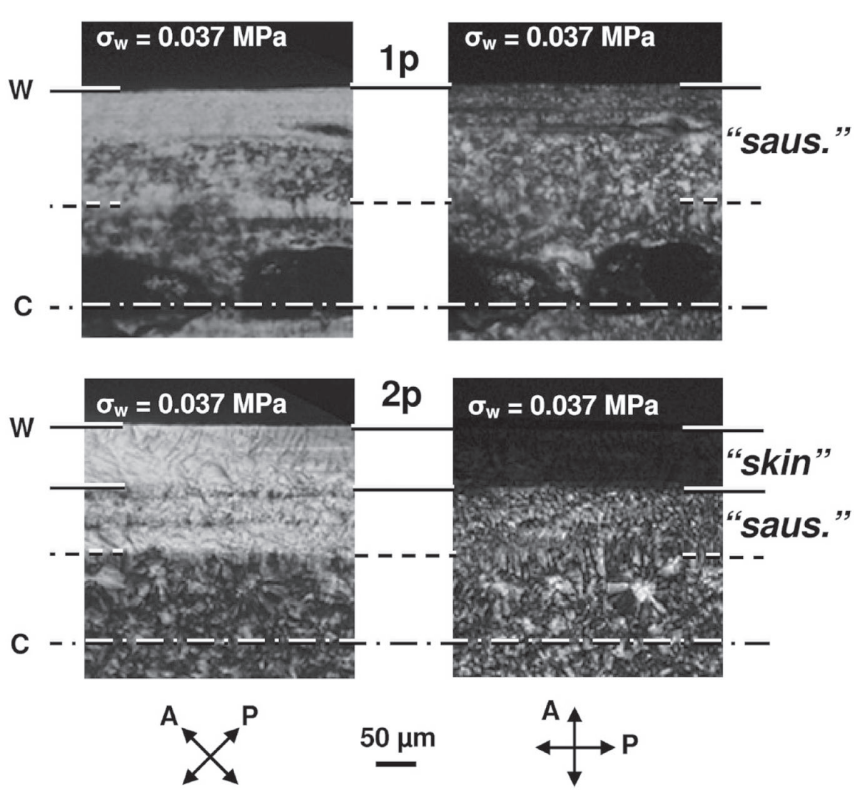

Figure 7. Ex-situ polarized optical micrographs for $1 p$ (top) and $2 p$ (bottom) crystallized at $137^{\circ} \mathrm{C}$ for 75 min after imposing a pulse of $\sigma_{\mathrm{w}}$ $=0.037 \mathrm{MPa}$. Extruded amounts were $\sim 100 \mathrm{mg}\left(t_{\mathrm{s}}=26\right.$ and $27 \mathrm{~s}$ for $1 p$ and $2 p$, respectively).

ented skin in the 2 wt \% blend $2 p$ (but not a highly oriented skin in 1p), Figure 7.

In general, as $\sigma_{\mathrm{w}}$ increased, the boundaries between morphological layers for a given $C_{\mathrm{L}}$ shifted farther from the wall (Figure 7 to Figure 5), consistent with a particular shear stress, denoted $\sigma_{i}$, where $i$ denotes the type of boundary. ${ }^{\mathrm{b}}$ The boundary of the highly oriented skin is generally sharp and uniform, allowing the stress at the boundary to be evaluated fairly precisely, which revealed that the boundary of the oriented skin coincided with a specific value of the shear stress. As $C_{\mathrm{L}}$ increases, this "threshold stress" $\sigma_{\text {skin }}$ decreases. The boundary between the unoriented core and the adjacent layer (either the sausage layer or the fine-grained layer) is more diffuse and variable. Nevertheless, these boundaries also shifted in a manner consistent with a threshold stress and yielded values of $\sigma_{\text {fine-gr }}$ or $\sigma_{\text {saus. }}$. Interestingly, samples showed either a fine-grained layer (if $C_{\mathrm{L}}<0.5 \mathrm{wt} \%$ ) or a "sausage" layer (if $C_{\mathrm{L}} \geq 0.5 \mathrm{wt} \%$ ), but not both (e.g., Figure 6 bottom). ${ }^{c}$

The threshold shear stress to induce the highly oriented skin morphology $\left(\sigma_{\text {skin }}\right)$ decreases strongly as the concentration of long chains $C_{\mathrm{L}}$ increases from 0 to the overlap concentration $C_{\mathrm{L}}{ }^{*}$ (Figure 8, top graph). Even the addition of just $0.125 \mathrm{wt} \%$ of $3.5 \mathrm{M}$ long chains (corresponding to $0.3 C_{\mathrm{L}}{ }^{*}$ ) reduces $\sigma_{\text {skin. }}$. In contrast, for concentration of long chains $C_{\mathrm{L}}$ $>C_{\mathrm{L}}{ }^{*}$, the effect of additional long chains on $\sigma_{\text {skin }}$ is weak. The threshold stresses to induce a fine-grained morphology $\sigma_{\text {fine-gr }}$ or to induce a sausage layer $\sigma_{\text {saus }}$ show a dependence with $C_{\mathrm{L}}$ similar to that of $\sigma_{\text {skin }}$. In the concentration range in which a fine-grained layer is observed (i.e., $C_{\mathrm{L}} / C_{\mathrm{L}}{ }^{*}<1.2$ ), $\sigma_{\text {fine-gr }}$ decreases like $\sigma_{\text {skin }}$ with the addition of long chains. Likewise, in the concentration range in which a sausage layer is observed $\left(C_{\mathrm{L}} / C_{\mathrm{L}}{ }^{*} \geq 1.2\right)$, the weak variation of $\sigma_{\text {skin }}$ with $C_{\mathrm{L}}$ for is also observed in $\sigma_{\text {saus. }}$.

The magnitude of the reduction in $\sigma_{\text {skin }}$ for $3.5 \mathrm{M}$ long chains is much greater than that observed previously for $1 \mathrm{M}$ long chains (Figure 8, bottom) in the same base resin (Base-PP)

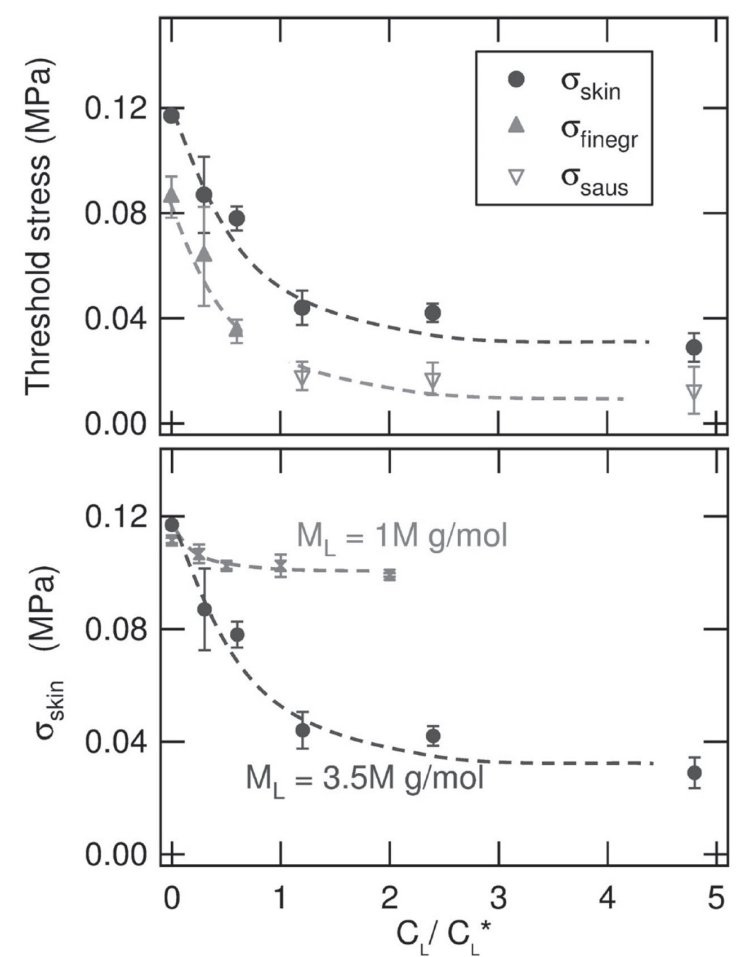

Figure 8. Top: effect of the concentration of $3.5 \mathrm{M}$ long chains $C_{\mathrm{L}}$ (relative to their overlap concentration $C_{\mathrm{L}}{ }^{*}$ ) on $\sigma_{\text {skin }}$ (for all $C_{\mathrm{L}} \mathrm{s}$ ), on $\sigma_{\text {fine-gr }}$ (for the smaller $C_{\mathrm{L}} \mathrm{s}$ ), and on $\sigma_{\text {saus }}$ (for the bigger $C_{\mathrm{L}} \mathrm{s}$ ) at $137^{\circ} \mathrm{C}$ and fixed total mass extruded. The dashed curves are for guiding the eye. Error bars refer to variations in the thicknesses of the skin, finegrained, and sausage areas. Bottom: comparison of the impact of $M_{L}$ (either $1 \mathrm{M}$ from earlier studies ${ }^{[27,54]}$ or $3.5 \mathrm{M}$ in the current study) of the long chains on $\sigma_{\text {skin. }} C_{\mathrm{L}}{ }^{*}$ is 0.0069 and $0.0036 \mathrm{~g} / \mathrm{cm}^{3}$ for $1 \mathrm{M}$ and $3.5 \mathrm{M}$ chains, respectively. The stresses reported in Seki et al. ${ }^{[27]}$ were corrected according to Thurman. ${ }^{[54]}$

subjected to the same flow-induced crystallization conditions as this study. ${ }^{[27,54]}$ For both $1 \mathrm{M}$ and $3.5 \mathrm{M}$ most of the reduction of $\sigma_{\text {skin }}$ occurs at low concentrations of long chains; the influence of $C_{\mathrm{L}}$ on $\sigma_{\text {skin }}$ is weak at $C_{\mathrm{L}} \geq 0.5 C_{\mathrm{L}}{ }^{*}$ for $1 \mathrm{M}$ and at $C_{\mathrm{L}} \geq 1.2 \mathrm{C}_{\mathrm{L}}{ }^{*}$ for $3.5 \mathrm{M}$. Interestingly, both of these threshold concentrations correspond to similar volume fractions of long chains $(0.4 \%$ for $1 \mathrm{M}$ and $0.5 \%$ for $3.5 \mathrm{M})$.

The final solid-state structure in quenched specimens was characterized using ex-situ wide-angle X-ray diffraction with the beam along the $\nabla \mathbf{v}$ direction, averaging over the various morphologies present in a given sample (Figure 1). These depth-averaged patterns are interpreted by building on previous microfocus X-ray patterns obtained for each different type of morphology ${ }^{[6]}$ and by comparing pairs of samples that only differ in the presence or absence of a given type of morphology. The diffraction patterns showed predominantly the a crystal morph of iPP. Weak reflections of the $\gamma$-morph were observed; no sign of the $\beta$-morph was found. The (110) reflection of the a-iPP crystal morph provides information about both the oriented parent lamellae (with $c$-axis along the flow direction) and their epitaxial daughter lamellae (at approximately $\pm 80^{\circ}$ ). For the lowest wall shear stress $\left(\sigma_{\mathrm{w}}=0.037 \mathrm{MPa}\right)$, the azimuthal distribution of the (110) intensity (Figure 9 top) shows strong orientation only for $2 \mathrm{p}$ (in accord with its thick highly oriented skin, Figure 7 bottom); the milder orientation seen in $1 p$ correlates with the presence of a "sausage" layer, but without 


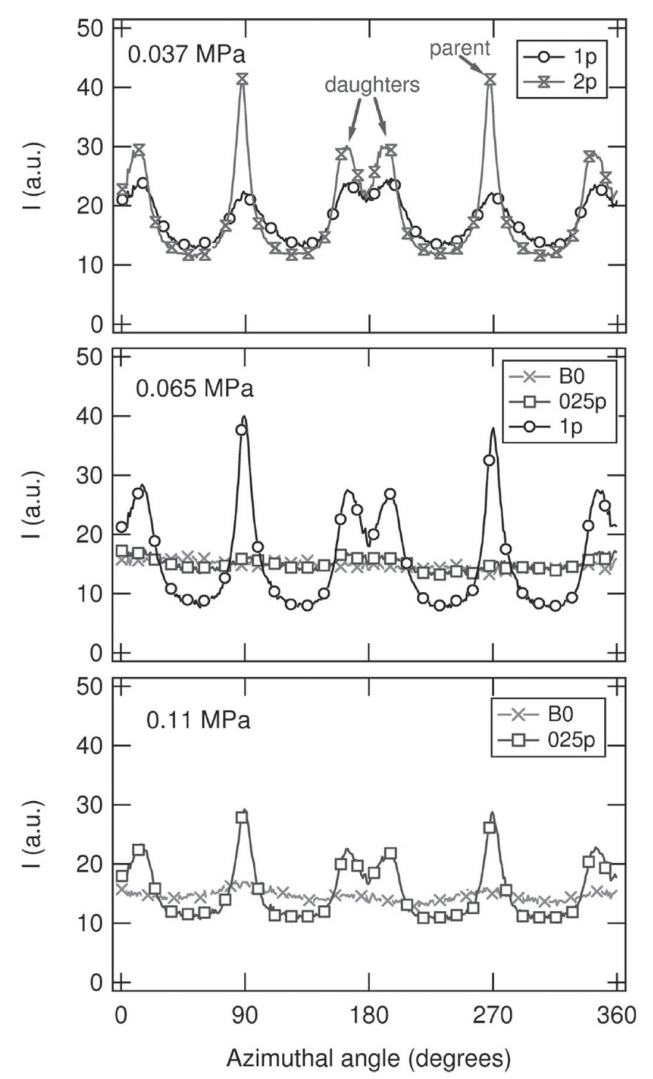

Figure 9. Ex-situ WAXD azimuthal distribution of the (110) reflection of $\alpha$-iPP. Samples were sheared at $137^{\circ} \mathrm{C}$ and $\sigma_{w}=0.037 \mathrm{MPa}$ (top), $0.065 \mathrm{MPa}$ (center), and $0.11 \mathrm{MPa}$ (bottom), and they were cooled and extracted after 75 min of isothermal crystallization. They correspond to the polarized optical micrographs shown in the previous figures: compare top to Figure 7, center to Figure 6, and bottom to Figure 5.

a highly oriented skin (Figure 7 top). The parent-to-daughter ratio is significantly greater for the $2 p$ sample than for $1 p$, as expected for a highly oriented skin. ${ }^{[6,55]}$ The next higher stress $\left(\sigma_{\mathrm{w}}=0.065 \mathrm{MPa}\right.$, Figure 9 center) induces a very high degree of orientation in $1 \mathrm{p}$, accompanied by a relatively high ratio of parent-to-daughter peaks (consistent with the oriented skin, Figure 6, bottom), whereas both B0 and 025p show an approximately isotropic orientation distribution (in accord with spherulitic morphologies, Figure 6, top and middle). The highest wall shear stress $\left(\sigma_{\mathrm{w}}=0.11 \mathrm{MPa}\right.$, Figure 9 bottom) induces significant orientation even in 025p (in accord with its oriented skin, Figure 5 bottom); however, B0 remains approximately isotropic (consistent with its spherulitic morphology, Figure 5 top).

Development of Semicrystalline Morphology in Situ. The kinetic processes leading to the observed effects of long chains on the final solid-state morphology are revealed by the development of crystallization during and after imposition of the shear pulse. During short-term shearing at the lowest wall shear stress applied, $\sigma_{\mathrm{w}}=0.037 \mathrm{MPa}$, only $2 \mathrm{p}$ developed a birefringence upturn (inset, Figure 10a): after the first $20 \mathrm{~s}$ of shearing, when the melt contribution dominates (nearly the same for $1 p$ and $2 p$ ), the birefringence of the $2 p$ sample increases strongly in a manner characteristic of formation of thread-like precursors and oriented crystallites (kebabs) on them. ${ }^{[25]}$ Upon cessation of flow, only a small fraction of the retardance of the $2 p$ sample relaxes (similar in magnitude to the drop in birefringence for $1 p)$. After the rapid relaxation, the birefringence of both $1 p$ and $2 p$ continues to increase, indicating growth of oriented crystals. For sample $2 p$ (which exhibits both a highly oriented skin and a sausage layer in ex-situ micrographs, Figure 7 bottom), the retardance increased rapidly, reaching a half-wave in $\sim 60 \mathrm{~s}$ (Figure 10a). In contrast, the retardance of $1 p$ (which in the ex-situ micrographs shows a sausage layer but no highly oriented skin, Figure 7 top) increased very slowly: at the time the retardance of $2 p$ reached a full wave (ca. $130 \mathrm{~s}$ ), the retardance of $1 p$ was only 0.02 -roughly $1 / 30$ th that of $2 p$. Even for this modest imposed stress, the time scale over which the samples became turbid $\left(t_{1 / 2} \sim 300 \mathrm{~s}\right.$, Figure $\left.10 \mathrm{~b}\right)$ was reduced by at least an order of magnitude relative to quiescent crystallization $\left(t_{1 / 2} \sim 10000 \mathrm{~s}\right.$ in Figure 3$)$. Interestingly, the $2 \mathrm{p}$ transmitted intensity decays in two steps, while the transmittance for $1 p$ decays monotonically (see Discussion section).

Increasing the wall shear stress to $\sigma_{\mathrm{w}}=0.065 \mathrm{MPa}$ at the same mass extruded, $T_{x^{\prime}}$ and isothermal hold time $(\sim 100$ $\mathrm{mg}, 137^{\circ} \mathrm{C}, 75 \mathrm{~min}$, as above) induces prolific formation of oriented thread-like precursors in $1 p$ manifested by the birefringence upturn during the shear pulse, which did not fully relax after flow was stopped (Figure 10c). The formation of thread-like precursors in $1 p$ accords with the highly oriented morphologies observed ex situ by POM (Figure 6 bottom) and WAXD (Figure 9, middle). Growth of oriented crystallites (kebabs) in 1p was manifested by an increase of retardance after cessation of flow. Neither B0 nor 025p exhibits a birefringence upturn, in accord with the absence of a highly oriented skin (Figure 6, top and middle). The sample that formed an oriented skin (1p) showed a two-step decay of the transmitted intensity (an early drop followed by a plateau, then a decay to zero, Figure 10d), while the samples with weak orientation (both 025p and B0) showed a monotonic decay. In all cases the samples became turbid much sooner than in the quiescent experiments (compare Figure 10d to Figure 3, note difference in scale).

Finally, the highest stress $\left(\sigma_{\mathrm{w}}=0.11 \mathrm{MPa}\right.$, with the same mass extruded, $T_{x^{\prime}}$ and isothermal hold time as above) induced a highly oriented skin in 025p, but not in B0 (Figure 5 and Figure 9 bottom). During the shear pulse, the in-situ birefringence initially rises to the same value for both $025 p$ and B0 (Figure 10e, inset), which corresponds to the melt flow birefringence (hence, average segmental orientation). A subsequent upturn in the birefringence is observed for $025 \mathrm{p}$, but not for B0, and after cessation of flow, the birefringence only partially relaxes for $025 \mathrm{p}$, and soon after it grows strongly (Figure 10e). The birefringence upturn during shear and the long-lived birefringence after shear are known to be signatures of prolific formation of oriented precursors which give rise to the highly oriented skin. ${ }^{[25]}$ In contrast, the birefringence completely decays for B0 after flow is stopped and does not significantly increase before the end of the experiment. The time scales for decay of transmittance (Figure 10f) are much faster than under quiescent conditions for both B0 and 025p; however, the shape of the decay is "two-step" for $025 \mathrm{p}$ and monotonic for B0.

For the experiments that exhibited an upturn in birefringence during flow, the time elapsed between the inception of shear and the appearance of the upturn $\left(t_{\mathrm{u}}\right)$ was estimated using the intersection of the steady-state melt flow birefringence and a line through the early upturn in birefringence. This procedure was feasible because the present bimodal 



Figure 10. Real-time optical retardance (left) and turbidity (right) measurements for different blends subjected to flow-induced crystallization at $137^{\circ} \mathrm{C}$ and different $\sigma_{\mathrm{w}^{\prime}}(\mathrm{a}, \mathrm{b}) 1 \mathrm{p}$ and $2 \mathrm{p}$ subjected to $\sigma_{\mathrm{w}}=0.037 \mathrm{MPa}$ and $t_{\mathrm{s}}=26$ and $27 \mathrm{~s}$, respectively. (c, d) B0, $025 \mathrm{p}$, and $1 \mathrm{p}$ subjected to $\sigma_{\mathrm{w}}$ $=0.065 \mathrm{MPa}$ and $t_{\mathrm{s}}=8.3,8.7$, and $12 \mathrm{~s}$, respectively. (e, f) B0 and $025 \mathrm{p}$ subjected to $\sigma_{\mathrm{w}}=0.11 \mathrm{MPa}$ and $t_{\mathrm{s}}=1.4$ and $2.4 \mathrm{~s}$, respectively. Extruded mass was $\sim 100 \mathrm{mg}$. Insets in left column show the details of the birefringence upturn during and right after shear.

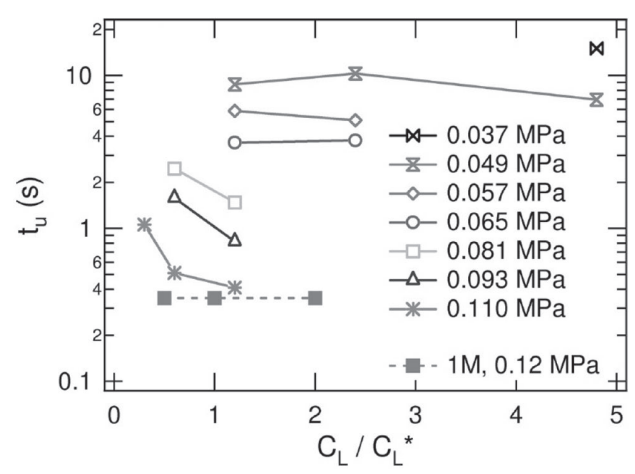

Figure 11. Time for upturn $\left(t_{u}\right)$ in birefringence signal during the shear pulse at $137^{\circ} \mathrm{C}$ for different wall shear stresses and $C_{\mathrm{L}} \mathrm{s}$ of $3.5 \mathrm{M}$ long chains. The data on $1 \mathrm{M}$ long chains and $0.12 \mathrm{MPa}$ from Seki et al. are also plotted.

blend behaved like those of Seki et al. in that an overshoot in melt birefringence did not occur upon inception of shear, which facilitated the determination of upturn times even when they were small in magnitude. ${ }^{[27]}$ In contrast, Ziegler-Natta polypropylenes typically exhibit a birefringence overshoot upon inception of shearing before reaching a plateau value. ${ }^{[2,3]}$

The "upturn time" $t_{\mathrm{u}}$ for the blends decreases strongly as $\sigma_{\mathrm{w}}$ increases at each concentration of long chains (Figure
11). For a fixed wall shear stress and 3.5M long chains, $t_{\mathrm{w}}$ initially decreases with increasing $C_{\mathrm{L}}$ (for $\left.C_{\mathrm{L}} / C_{\mathrm{L}}{ }^{*} \leq 1.2\right)$, then becomes insensitive to $C_{\mathrm{L}}$ at higher concentrations $\left(C_{\mathrm{L}} / C_{\mathrm{L}}\right.$ * 21.2). Interestingly, $C_{\mathrm{L}} / C_{\mathrm{L}}{ }^{*}=1.2$ is also the concentration of $3.5 \mathrm{M}$ long chains at which $\sigma_{\text {skin }}$ became insensitive to $C_{\mathrm{L}}$ (Figure 8). This saturation behavior is in accord with the steady value of $t_{\mathrm{u}}$ observed for the $1 \mathrm{M}$ bimodal blends of Seki et al., where all three $C_{\mathrm{L}}$ that showed an upturn belonged to the range where the effect of $1 \mathrm{M}$ long chains had already saturated (Figure 11). ${ }^{[27,54]}$

\section{Discussion}

To examine the changes in behavior associated with the transition from long-chain orientation to long-chain stretching, the present series of binary blends is designed such that the ratio of the long-chain Rouse time to the short-chain disengagement time, $\tau_{R, L} / \tau_{D, S^{\prime}}$ largely determines whether or not the long chains undergo chain stretching. The blends all have zero shear viscosity close to that of the pure short chains, specifically $\eta_{\text {blend }} \in\left(\eta_{S^{\prime}}, 3 \eta_{S}\right)$. Therefore, all of the blends can be viewed as having viscosity that scales with the product of the plateau modulus of iPP $G_{N}{ }^{\circ}$ and the shortchain disengagement time $\tau_{D, S}$ (empty square on the timeline in Figure 12): $\eta_{S} \approx \tau_{D, S} G_{N}{ }^{0}$. Thus, for a given applied shear stress $\sigma$, the resulting shear rate scales as $\sim \sigma /\left(\tau_{\mathrm{D}, S} G_{\mathrm{N}}{ }^{\circ}\right)$. Consequently, chain stretching of long chains is expected when 


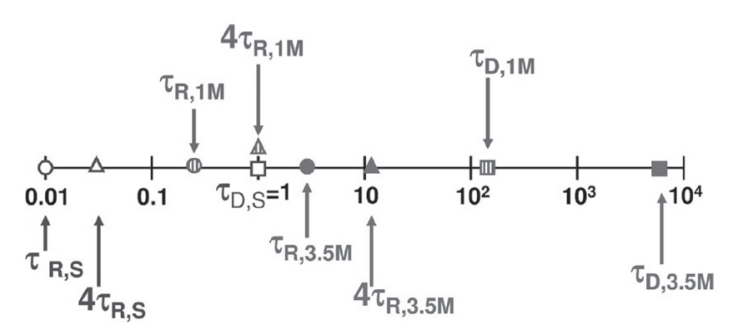

Figure 12. Retraction times for untethered and tethered short chain $\left(\mathrm{T}_{\mathrm{R}, \mathrm{S}}, 4 \mathrm{~T}_{\mathrm{R}, \mathrm{S}}\right), 1 \mathrm{M}$ long chains $\left(\mathrm{T}_{\mathrm{R}, 1 \mathrm{M}}, 4 \mathrm{~T}_{\mathrm{R}, 1 \mathrm{M}}\right)$, and $3.5 \mathrm{M}$ long chains $\left(T_{R, 3.5 \mathrm{M}}, 4 \mathrm{~T}_{R, 3.5 \mathrm{M}}\right)$ relative to the short chain disengagement time, $\mathrm{T}_{\mathrm{D}, \mathrm{S}}$. Reptation times of $1 \mathrm{M}$ and $3.5 \mathrm{M}$ are also indicated $\left(\mathrm{T}_{\mathrm{D}, 1 \mathrm{M}}\right.$ and $\left.\mathrm{T}_{\mathrm{D}, 3.5 \mathrm{M}}\right)$.

$\sigma /\left(\tau_{\mathrm{D}, \mathrm{S}} G_{\mathrm{N}}{ }^{\circ}\right)>\left(1 / \tau_{\mathrm{R}, \mathrm{L}}\right)$ or, equivalently, when $\tau_{\mathrm{R}, \mathrm{L}} / \tau_{\mathrm{D}, \mathrm{S}}>$ $G_{N} \%$. Here, we examine a range of shear stresses that corresponds to $G_{N} \% \sigma$ from 4 to 10 . Long chains of $3.5 \mathrm{M}$ provide $\tau_{R, L} / \tau_{D, S} \approx 3$, such that the highest stress imposed in this study approaches the transition from long-chain orientation to long-chain stretching. To our knowledge, this is the first set of experiments in which the deformation rate reaches the threshold for chain stretching for long chains of well-defined length and concentration.

In addition to the relaxation dynamics of free chains in the bulk, the dynamics of chains attached to a precursor may be important in the physics at the ends of a rapidly propagating shish. Under conditions that induce a highly oriented skin, shish can increase in length at a rate on the order of $10 \mu \mathrm{m} / \mathrm{s}$; ${ }^{d}$ thus, successive ordering events near a propagating tip occur orders of magnitude faster than in the rest of the melt. Perhaps the relative ease of stretching of a tethered long chain contributes to the rapid ordering that occurs near a propagating tip. The chain length equilibration time of a grafted chain may be estimated using a simple argument. A tethered chain of a given length has Rouse modes equivalent to a free chain of twice that length. Since the Rouse time $\tau_{R}$ varies quadratically with chain length, a dangling strand with most of the length of the free chain will have roughly 4 -fold longer Rouse time $\left(4 \tau_{R}\right)$ than a free chain of the same length.

Effect of $M_{\mathrm{L}} / M_{\mathrm{S}}$ on Long Chain Stretching. The stronger decrease of $\sigma_{\text {skin }}$ upon addition of $3.5 \mathrm{M}$ long chains than for $1 \mathrm{M}$ long chains (Figure 8 bottom) can be ascribed to the onset of long chain stretching as $M_{L} / M_{S}$ increases. Free long chains of $1 \mathrm{M} \mathrm{g} / \mathrm{mol}$ are unlikely to undergo stretching $\left(\tau_{\mathrm{R}, 1 \mathrm{M}}<\tau_{\mathrm{D}, \mathrm{S}}\right.$ : compare striped circle to open square in Figure 12), based on

$$
\tau_{\mathrm{R}, \mathrm{L}}=\frac{N_{\mathrm{e}}}{3 N_{\mathrm{S}}}\left(\frac{N_{\mathrm{L}}}{N_{\mathrm{S}}}\right)^{2} \tau_{\mathrm{D}, \mathrm{S}}
$$

where $N_{\mathrm{e}}$ is the number of monomers in an entanglement strand, and $N_{\mathrm{S}}, N_{\mathrm{L}}$ are the number of monomers in a short and a long chain, respectively. ${ }^{[56]}$ Only for an end-adsorbed $1 \mathrm{Mg} / \mathrm{mol}$ long chain would stretching be plausible $\left(4 \tau_{\mathrm{R}, 1 \mathrm{M}} \approx\right.$ $\tau_{D, S}$, striped triangle and open square, Figure 12). Increasing the length of the long chains to $3.5 \mathrm{M} \mathrm{g} / \mathrm{mol}$ opens the possibility of chain stretching in the bulk $\left(\tau_{R, 3.5 \mathrm{M}}>\tau_{\mathrm{D}, \mathrm{S}}\right.$ : compare filled circle to open square in Figure 12), and adsorbed 3.5M long chains would be expected to experience chain stretching $\left(4 \tau_{R, 3.5 \mathrm{M}}>10 \tau_{\mathrm{D}, S^{\prime}}\right.$ filled triangle vs open square in Figure 12).

Two Types of Oriented Morphologies. In contrast to binary blends using $1 \mathrm{M}$ long chains, two types of oriented regions form in the $3.5 \mathrm{M}$ bimodal blends - a highly oriented skin and regions populated with "sausage-like" structures. Both the highly oriented skin and the sausage layer develop

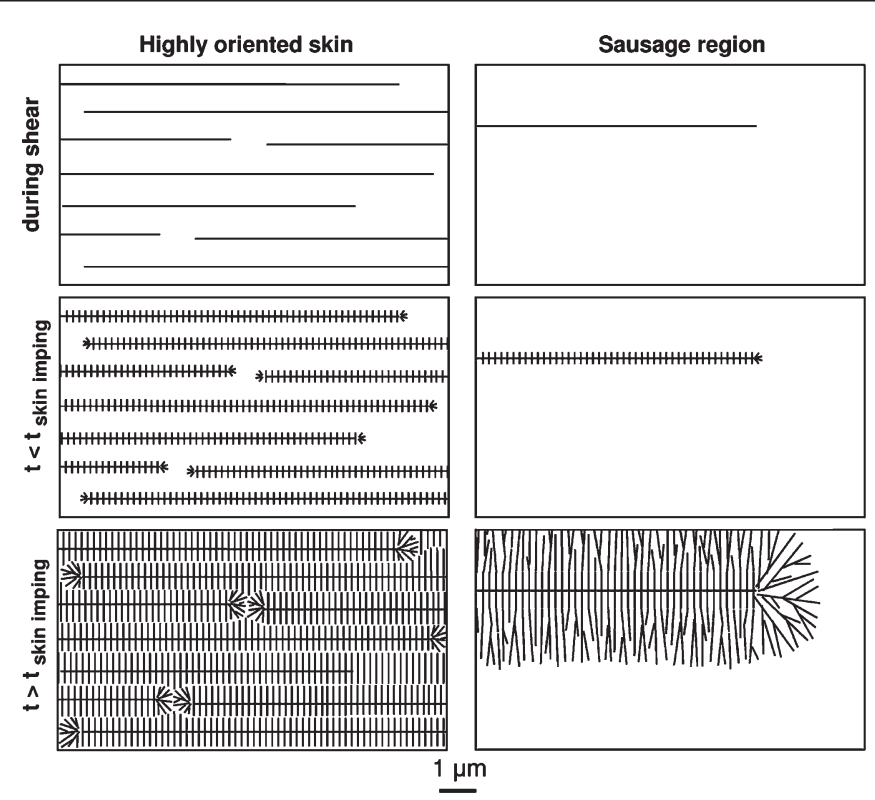

Figure 13. Schematic of formation and development of highly oriented skin (left column) and sausage region (right column). Top: shear produces a much higher concentration of thread-like precursors in the skin than in the sausage region. Middle: after cessation of flow (but before impingement of skin) oriented lamellae (i.e., kebabs) grow off the thread-like precursors. Bottom: in the skin, oriented lamellae impinge with one another at short times (due to small interdistances), while in the sausage region, oriented lamellae continue to grow off the central thread and are able to undergo noncrystallographic branching and splaying at farther distance, decreasing their degree of orientation.

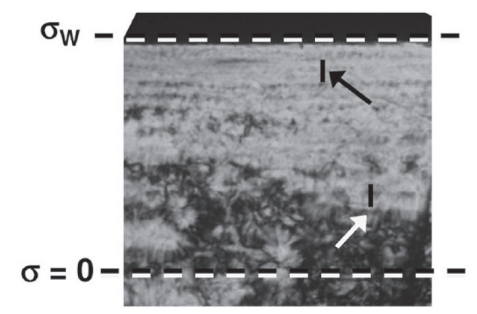

Figure 14. Polarized optical micrographs of $1 \mathrm{p}$ sheared at $137^{\circ} \mathrm{C}$ with $\sigma_{\mathrm{W}}=0.044 \mathrm{MPa}$ below $\sigma^{*}{ }_{\text {skin }}$ but above $\sigma^{*}$ saus showing typical region populated with sausages. The vertical black lines have a length of 25 $\mu \mathrm{m}$ and encompass approximately $2-3$ sausages.

from oriented thread-like precursors-although with very different concentrations (Figure 13). The highly oriented skin is templated by long threads that are closely spaced (submicrometer spacing between the shish). ${ }^{[1,27,57]}$ Indeed, electron micrographs of the highly oriented skin have shown $>1$ ( $\mu \mathrm{m}$ of shish $) /\left(\mu \mathrm{m}^{3}\right){ }^{[25]}$ In contrast, the distances between sausages - and therefore, between the threads running down their middle-are typically on the order of $\sim 10 \mu \mathrm{m}$ or more (large enough to be observed by optical microscopy, Figure 6 bottom, Figure 7, Figure 14). Therefore, we can estimate that the order of magnitude of shish concentration is $\sim 0.01$ ( $\mu \mathrm{m}$ of shish $) /\left(\mu \mathrm{m}^{3}\right)$ or less in the sausage layer.

The substantial difference in concentration of threads between the "sausage layer" and the highly oriented skin is evident in real-time measures of structure formation during and after short-term shear. First, the upturn in birefringence during shear, which correlates with subsequent formation of a highly oriented skin (insets of Figure 10a,c, $\mathrm{e}^{[3,25]}$ ), was ab- 
sent when only sausages formed (inset of Figure 10a). Evidently, the thread-like precursors in the sausage layer are dilute: their birefringence and any due to kebabs grown during shear is negligible relative to the melt flow birefringence (Figure 13 top, compare left vs right). Second, after cessation of shear, the rate of oriented crystallization is vastly lower when only sausage layers form than when an oriented skin forms ${ }^{[6]}$ (Figure 10a,c,e). After the melt relaxes, growth of kebabs occurs with the linear growth rate typical of quiescent crystallization, ${ }^{[58]}$ which is - by design - the same for all samples in the present study. Therefore, the slower oriented crystallization in the sausage layer unambiguously indicates that it has a much lower concentration of shish than the oriented skin (Figure 13 middle, compare left vs right). Third, the small and relatively uniform distances between threads in the highly oriented skin-but not in the "sausage layer" - lead to relatively short impingement times, evidenced by an abrupt decrease in the rate of oriented crystallization ${ }^{[57]}$ and a plateau or even an increase of transmittance ${ }^{[3,59]}$ (compare Figure 15a-c vs Figure $15 \mathrm{~d}$ ). For example, impingement at $\sim 100 \mathrm{~s}$ corresponds to a distance of $\sim 1 \mu \mathrm{m}$ between shish in the highly oriented skin (based on the linear growth rate of $G \sim 0.003 \mu \mathrm{m} / \mathrm{s}$ for a similar iPP at $137 C^{[60]}$ ). In contrast, sausage layers do not show signs of impingement in situ because the distance between oriented precursors is much greater than the distance a growth front can advance before turbidity precludes further optical measurements (Figure 13 bottom, compare left vs right). For example, after shearing $1 \mathrm{p}$ at $\sigma_{\mathrm{w}}=0.037 \mathrm{MPa}$, the distance between oriented precursors is $\sim 20 \mu \mathrm{m}$ (Figure 7 top left), which is much greater than the $\sim 1.5 \mu \mathrm{m}$ distance the growth front can advance before the sample becomes turbid ( $\sim 400 \mathrm{~s}$, Figure $10 \mathrm{~b})$. Thus, there is a clear distinction between the highly oriented skin and the sausage layer.

The significantly different concentrations of shish in the highly oriented skin and the sausage layer are consistent with the degree of orientation observed in the final solid state, which is much greater in samples that have a highly oriented skin than those with only sausage layers (Figure 9 , top). In the highly oriented skin, impingement occurs at relatively short times and at small distances from the shish where oriented lamellae are laterally constrained, and therefore, all their growth occurs with a high degree of orientation (Figure 13, bottom left). In contrast, in the sausage layer lamellae are able to grow farther from their central shish, giving them more time and space to undergo noncrystallographic branching and splaying, thus decreasing their orientation correlation (Figure 13, bottom right). In addition, spherulitic structures interdispersed between the sausage structures arise due to point nuclei formed during shear and due to the nonisothermal formation of point-like nuclei during cooling (illustrated in Figure 4, right). These interdispersed spherulitic structures further contribute to the lower degree of orientation of the fully solidified sausage layer.

Interestingly, the boundary between the sausage region and the highly oriented skin is rather sharp: A discontinuity in birefringence is evident at the boundary, even for samples with a relatively high concentration of sausages near the highly oriented skin (Figure 6 bottom, Figure 7 bottom). This suggests that for our $3.5 \mathrm{M}$ blends there is a qualitative change in the ability to prolifically create high concentrations of thread-like precursors at $\sigma_{\text {skin }}-$ not a gradual transitionwhich inspires the conceptual model proposed below.

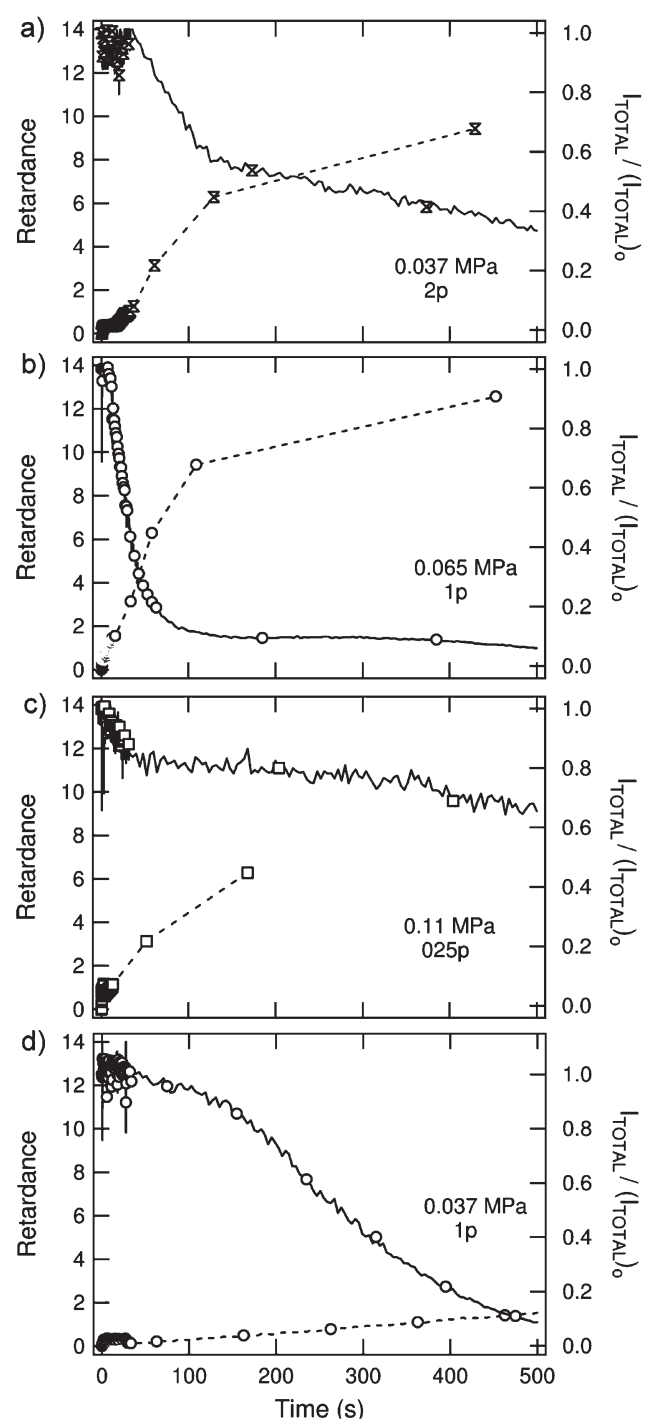

Figure 15. Impingement signatures in retardance (dashed trace) and turbidity (solid trace) at $137^{\circ} \mathrm{C}$ for samples that develop a highly oriented skin (a) $2 p$ at $\sigma_{\mathrm{w}}=0.037 \mathrm{MPa}$, (b) $1 \mathrm{p}$ at $\sigma_{\mathrm{w}}=0.065 \mathrm{MPa}$, and (c) $025 \mathrm{p}$ at $\sigma_{\mathrm{w}}=0.11 \mathrm{MPa}$ vs sample that only develops sausage region (d) $1 \mathrm{p}$ at $\sigma_{\mathrm{w}}=0.037 \mathrm{MPa}$.

Conceptual Model for Formation of Thread-like Precursors. In the following, we extend an earlier conceptual model ${ }^{[27]}$ to explain the role of the long chains in formation of thread-like precursors, building upon the idea that shish form in the flow direction starting from point-like nuclei. Prolific formation of thread-like nuclei does not occur until after a significant number of point-nuclei have formed during shear flow, suggesting that their presence is necessary. $[1,28,31,32,61]$ Beyond that point, the process of shish formation is still the subject of debate. An often-stated mechanism is the aggregation of extended long chains; ${ }^{[38,62]}$ but recent experimental results showing that thread precursors are not enriched in long chains disfavor this mechanism. ${ }^{[14]}$ Another hypothesis suggests that formation of shish results from the coalescence of point nuclei once their number becomes sufficiently large. ${ }^{[28]}$ However, point precursors are typically several micrometers apart, ${ }^{\mathrm{e}}$ and the diffusivity of multichain aggregates is expected to be slower than that of individual molecules. Thus, it is difficult to devise a mechanism that 
could bring a sufficient number of point-like nuclei together and position them into a line fast enough to produce $\sim 10$ $\mu \mathrm{m}$ of shish per second. Instead, the morphologies generated by shearing (fine grained, sausage, and highly oriented skin) suggest that special conditions are created immediately upstream (or downstream) of a previously formed precursor. For this reason, we build upon a proposed mechanism that treats formation of thread-like precursors as a quasi-stationary process in which growth propagates upstream and downstream from the primary point-like nuclei; i.e., the thread-like precursor grows in length from its tips. ${ }^{[1,27]}$

Nanoscopic regions near an existing thread-like precursor locally support a much higher rate of ordering events than the rest of the sheared melt-by orders of magnitude. The local rate of ordering events at a propagating tip can be approximated from the propagation velocity $\left(\sim 10 \mu \mathrm{m} \mathrm{s}^{-1}\right)$ of a shish. If shish increase in length by ordering events immediately adjacent to the tip (i.e., within a distance of $R_{\mathrm{g}}$ of a short chain, $\sim 10$ $\left.\mathrm{nm}^{\mathrm{f}}\right)$, an upper bound of the local rate of transforming melt into ordered structure corresponds to one ordering event per

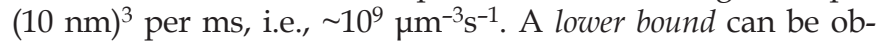
tained by speculating that ordering at distances up to $\sim 100 \mathrm{~nm}$ from the propagating tip can add to the growing shish (on the order of the $R_{\mathrm{g}}$ of a $3.5 \mathrm{M}$ long chain or perhaps by a sequence

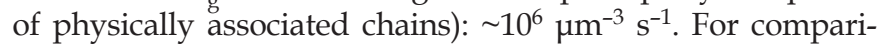
son, the rate of formation of point-like precursors in the bulk of the melt can be estimated from the distance between point nuclei in fine-grained layers, i.e., $\sim 10 \mu \mathrm{m}$ apart; thus, pointlike precursor formation occurs at rates less than one event per $(10 \mu \mathrm{m})^{3}$ per s (i.e., $\left.\sim 10^{-3} \mu \mathrm{m}^{-3} \mathrm{~s}^{-1}\right)$. A generous upper bound on this bulk ordering rate can be obtained by speculating that only 1-in-1000 precursors go on to become active nuclei: $\sim 10^{\circ} \mu \mathrm{m}^{-3} \mathrm{~s}^{-1}$. Even with a conservative bound on the local rate of ordering events at a growing tip and a generous bound on the rate of ordering events in the melt as a whole, they differ by 6 orders of magnitude. Because of this, we focus on the physical processes that might occur locally, very near point-like nuclei-but not in the bulk of the melt.

To account for the formation of both the sausage region and the highly oriented skin, we distinguish two different processes in the development of a thread from a point-like precursor: initiation and propagation. Initiation of threads must occur profusely at the high stresses $\left(\sigma>\sigma_{\text {skin }}\right)$ that produce high concentrations of shish. On the basis of the sharp boundary of the highly oriented skin, we consider physics that may explain a threshold stress for prolific initiation of threads. Propagation is essential to the formation of long threads, whether closely spaced or far apart. The morphology of the sausage layer indicates that the shish can propagate to great lengths (tens of micrometers) at stresses that can be much lower than the threshold for prolific initiation $\left(\sigma_{\text {saus }} \sim 1 /{ }_{2} \sigma_{\text {skin }}\right)$. The present model accounts for both a threshold stress $\sigma_{\text {init }}$ to activate a point-like precursor into a propagating thread and a lower threshold stress to propagate shish $\sigma_{\text {prop }}$. After describing the conceptual model, we show that it also accounts for the observed effects of $M_{\mathrm{L}}(1 \mathrm{M}$ vs $3.5 \mathrm{M}$ long chains) and of $C_{\mathrm{L}}$ on $\sigma_{\text {skin }}$ and $\sigma_{\text {saus }}$.

Initiation of a Thread. The longest molecules in the melt are known to play a particularly important role in formation of thread-like precursors, and it is known that they access greater-than-average degrees of orientation or stretch relative to the matrix of shorter chains. ${ }^{[45]}$ However, we have

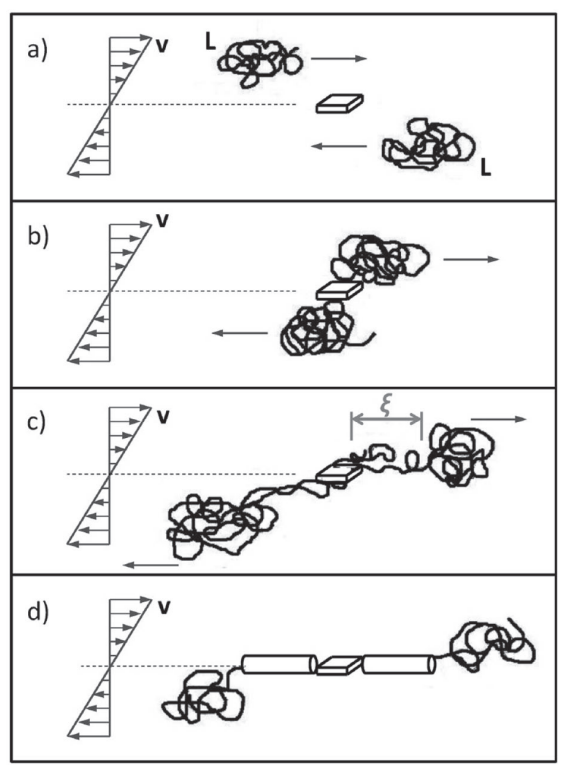

Figure 16. Schematic of initiation of thread-like precursors. Relative velocity profile is shown on the left. The dashed line indicates the streamline of an already present point nuclei-not the center of the channel. Only long chains are shown (short chains that are also present, able to adsorb and are incorporated into the thread are omitted). Long chains are convected toward a point nuclei (a) and adsorb onto it (b). A characteristic length " $\xi$ " near the tethering point develops a local high level of orientation and stretch (c) that promotes a local enhancement of ordering events, thus initiating the thread (d).

seen above that the degree of orientation or stretch of the long chains in the bulk melt only explains ordering events at a rate of $\sim 10^{\circ} \mu \mathrm{m}^{-3} \mathrm{~s}^{-1}$ or less - not sufficient to generate shish. Therefore, like Seki et al.,[27] we consider the local increase of orientation that may result from the adsorption of a long chain on a point-like nucleus during shear (Figure 16a,b). (Short chains also adsorb, but their relaxation is so rapid that, even when tethered, they do not stretch, Figure 12.) Adsorption requires either diffusive or convective transport of the chain to the surface of the point-nuclei. If shearing continues after a long chain attaches to a point-like precursor, portions of the chain can be convected away from the nucleus, producing a "streamer" that emanates from the point-like nucleus. ${ }^{[27]}$ Tension in the segments of the long chain close to the tethering point induces a local level of orientation and stretch that is not found elsewhere in the melt (Figure 16c); thus, a characteristic length $\xi$ of a tethered long chain will have particularly high segmental orientation, while segments near the free end are only slightly perturbed. If $\xi$ is of the same order as $R_{\mathrm{g}}$ of the long chains, then $3.5 \mathrm{M}$ chains might have $\xi$ of $\sim 100$ $\mathrm{nm}$. Neighboring chains that are not themselves stretched are influenced by the enhanced orientation and stretch of the $\xi$-section(s) of long chain(s) that are tethered to the precursor. Thus, the conditions generated immediately upstream and downstream of a precursor are exceptional, providing a plausible explanation for a local enhancement of the rate of ordering events by orders of magnitude (perhaps $\sim 10^{6} \mathrm{\mu m}^{-3} \mathrm{~s}^{-1}$ ) that initiates thread formation (Figure 16d).

In this physical picture, the length of the long chains is expected to have a very strong effect. Increasing $M_{\mathrm{L}}$ results in both stronger orientation of the chain segments near the tether point (due to the greater "drag force" on the dangling long chain) and longer "reach" of the $\xi$ portion in which significant 


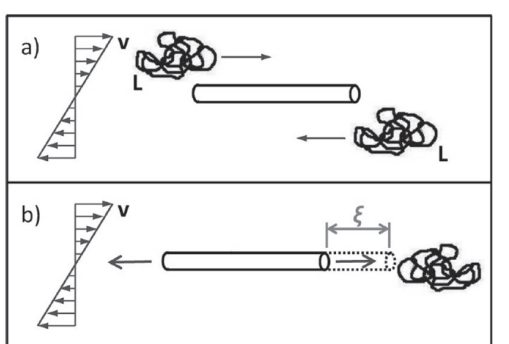

Figure 17. Schematic of propagation of thread precursors. The growth front can propagate (a) via adsorption of convected long chains or (b) by interception of long chains by the propagating tip.

stretching occurs (Figure 16c). Thus, the present conceptual model could explain the decrease in the threshold stress for thread initiation, $\sigma_{\text {init }}$ observed with increasing $M_{\mathrm{L}} / M_{\mathrm{S}}$.

This physical picture is also compatible with the nonlinear effects of long-chain concentration $C_{\mathrm{L}^{\prime}}$ particularly as it approaches long-chain overlap $C_{\mathrm{L}}{ }^{*}$. Elsewhere in the melt it is very unlikely that two long chains simultaneously have stretched portions in proximity to each other. In contrast, adsorption of two (or more) long chains to a given point-like precursor provides spatiotemporal correlation of stretched segments. As $C_{\mathrm{L}}$ increases, the probability that two or more long chains attach to the same point precursor increases. In turn, increasing the number of long chain "streamers" attached to a given precursor would, at a given stress, increase the average orientation in the volume in which the " $\xi$ portions" overlap. Consequently, the stress required to produce the threshold level of segmental orientation (within a distance $\xi$ of the precursor) to initiate propagation, $\sigma_{\text {init' }}$ would initially decrease as $C_{\mathrm{L}}$ increases. Experimentally, it is observed that the effect of increasing $C_{\mathrm{L}}$ becomes weak beyond the long-chain overlap concentration (e.g., for $C_{\mathrm{L}}>1.2 C_{\mathrm{L}}{ }^{*}$ in Figure 8). When $C_{\mathrm{L}}$ reaches $C_{\mathrm{L}}{ }^{*}$, a long chain is almost always in the vicinity of the precursor; perhaps that is sufficient to saturate the capacity of the precursor for adsorption, possibly explaining the mild effect of $C_{\mathrm{L}}$ on $\sigma_{\text {init }}$ once it is greater than $C_{\mathrm{L}}{ }^{*}$.

Propagating a Thread. After a shish has been initiated from a point nucleus, its further propagation is facilitated by the existence of the " $\xi$ portions". Propagation of shish must involve successive attachments of long chains to the tips of the growing shish, since many long chains are involved in the formation of a typical shish. Shish are typically much longer than the reach of a single chain, making it impossible to explain shish formation with just one or even a few long chains.g Under conditions that produce a highly oriented skin, long chains are present in the shish at a concentration that matches their concentration in the surrounding melt, ${ }^{[14]}$ suggesting that at least one long chain per $\sim 100 \mathrm{~nm}$ of shish is involved in the process of forming that shish. Although the precise nature of the propagating front is not known, we consider two different ways that long chains might play a role: long chains might adsorb to the shish as they are convected past (as suggested above for initiation, Figure 17a) or a shish might incorporate long chains in its path by overtaking them (Figure 17b, an additional mechanism enabled by the " $\xi$ portions"). Thus, the long chains required to maintain the propagating front may be supplied by incorporation or adsorption or both. When this occurs, new streamers with a stretched portion $\xi$ form and the propagation process continues.

Propagation is expected to be sensitive to the probability of finding another long chain within a distance $\xi$ of the propagating tip. When $C_{\mathrm{L}}<C_{\mathrm{L}}{ }^{*}$, a long chain may not be available near the tip of the shish. On one hand, if the length $\xi$ (Figure 16c) spans the characteristic center-to-center distance between dilute long chains, the thread is likely to "intercept" a long chain. The newly added long chain will extend a streamer on the order of $\sim \xi$ and "catch" another long chain, resulting in a quasi-stationary process. Propagation by interception would thus depend strongly on the relative magnitude of $C_{\mathrm{L}}$ and of the reach of $\xi$ (which increases with increasing $M_{\mathrm{L}}$ and $\sigma$ ). On the other hand, adsorption of a long chain that is flowing past the tip is limited by the average time required for a long chain to arrive at the propagating tip, which depends on the distance between long chains and their relative velocity with respect to the tip $(\sim$ $R_{\mathrm{g}, \mathrm{L}} \times$ [shear rate]). The probability of adsorption events also increases with increasing $C_{\mathrm{L}^{\prime}} \sigma$, and $M_{\mathrm{L}}$. Therefore, for $C_{\mathrm{L}}<$ $C_{\mathrm{L}}{ }^{*}$, there is an interplay between $C_{\mathrm{L}}, M_{\mathrm{L}} / M_{\mathrm{S}^{\prime}}$ and $\sigma$ that determines whether or not propagation will occur and how rapidly it will advance. Once $C_{\mathrm{L}}{ }^{*}$ has been reached, finding a long chain nearby should be relatively easy, so further increase of long chain concentration may have a weak effect on propagation. Overall, this physical picture suggests that the required stress for propagation $\sigma_{\text {prop }}$ may be less than $\sigma_{\text {init }}$ due to the $\xi$-portions that are present after the initiation step.

Physical Significance of the Boundary between Sausages and Skin. The conceptual model above can capture the existence of two distinct oriented morphologies: both regions satisfy the condition for propagation of a thread, but only the highly oriented skin satisfies the condition for prolific "initiation". The dilute threads characteristic of sausage regions suggest that they form at stresses below $\sigma_{\text {init' }}$ where very few of the point-like precursors convert to propagating shish. We speculate that in the neighborhood of particles (e.g., catalyst fragments, dust) the stress could exceed $\sigma_{\text {init' }}$ The formation of sausages depends strongly on $C_{\mathrm{L}}$ : they are most evident near and above $C_{\mathrm{L}}{ }^{*}$ for $3.5 \mathrm{M}$ chains in binary blends that readily propagate long shish, suggesting that once a relatively infrequent event starts the shish, the propagation continues relatively easily if $C_{\mathrm{L}}>C_{\mathrm{L}}{ }^{*}$ (i.e., $\sigma_{\text {init }}>\sigma_{\text {prop }}$ ).

How Long Is "Long" Enough? The comparison of the present binary blends with $3.5 \mathrm{M} \mathrm{g} / \mathrm{mol}$ long chains and our earlier work in the same base resin with $\sim 1 \mathrm{M} \mathrm{g} / \mathrm{mol}$ long chains shows qualitatively different effects. While $1 \mathrm{M}$ long chains reduce $\sigma_{\text {skin' }}$, the effects are much weaker than those seen with 3.5M long chains (Figure 8 bottom). This suggests that $1 \mathrm{M}$ long chains are just at the threshold length required to influence the transition to oriented growth in a matrix of $186 \mathrm{~K}$ iPP. Even if tethered at its end, the $1 \mathrm{M}$ long chain has a Rouse time comparable to the reptation time of the matrix, which controls the shear rate in the present experiments $\left(4 \tau_{R, 1 M} \approx \tau_{S^{\prime}}\right.$ Figure 12). Consequently, the $1 \mathrm{M}$ long chains might require a much higher stress to develop an appreciable stretched $\xi$-portion, while an adsorbed $3.5 \mathrm{M}$ chain $\left(4 \tau_{\mathrm{R}, 3.5 \mathrm{M}}>\right.$ $10 \tau_{\mathrm{S}}$ ) may undergo facile formation of a stretched $\xi$-portion. In turn, this may explain why the addition of as little as $0.3 C_{\mathrm{L}}{ }^{*}$ has a strong effect for $3.5 \mathrm{M}$, while very weak changes in flow-induced crystallization were seen at $0.25 C_{\mathrm{L}}{ }^{*}$ for $1 \mathrm{M}$.

The absence of a sausage layer in the case of $M_{\mathrm{L}}=1 \mathrm{M}$ may be further evidence that it is a borderline case, indicating that $\sigma_{\text {skin }} \approx \sigma_{\text {saus }}$ (equivalently $\sigma_{\text {init }} \approx \sigma_{\text {prop }}$ ). In contrast, the more pronounced $\xi$-portion of tethered 3.5M chains (Fig- 
ure 16c) gives them greater reach, which would facilitate addition of long chains by incorporation-thus reducing the threshold stress for propagation relative to that for initiation. If the $1 \mathrm{M}$ chains do represent a marginal case, the criterion $4 \tau_{R, L^{*}} \approx \tau_{S}$ may provide a useful estimate of the minimum $M_{\mathrm{L}} / M_{\mathrm{S}}$ required (in a matrix with reptation time $\tau_{\mathrm{S}}$ ) for a small concentration of long chains to significantly modify initiation and propagation of shish.

How Many Long Chains Are Enough? As noted earlier, ${ }^{[27]}$ the dramatic enhancement of shish formation by long chains is not a single chain effect. The nonlinear decrease of $\sigma_{\text {skin }}$ as concentration $C_{\mathrm{L}}$ increases to $C_{\mathrm{L}}{ }^{*}$ (Figure 8 top) is explained in the conceptual model by the nonlinear effect of having two or more long chains attached to a precursor, thus reducing the macroscopic stress $\sigma$ required to create sufficient local orientation to initiate or propagate a shish. If it were a single chain effect, at any given stress $\sigma$, the rate of initiation and propagation of threads would simply increase in proportion to $C_{\mathrm{L}}$ and the threshold stresses would not change significantly. In contrast, at a stress of $\sigma_{\mathrm{w}}=$ $0.065 \mathrm{MPa}$, the effect of long chains qualitatively changes as $C_{\mathrm{L}}$ increases 4 -fold from $0.6 \mathrm{C}_{\mathrm{L}}{ }^{*}$ to $2.4 \mathrm{C}_{\mathrm{L}}{ }^{*}(025 \mathrm{p}$ to $1 \mathrm{p}$, Figure 6 ), which cannot be explained by a simple 4 -fold increase in the rate of processes active in the $C_{\mathrm{L}}=0.6 \mathrm{C}_{\mathrm{L}}{ }^{*}$ material.

It is important to note that the collaborative effect of long chains in the conceptual model does not require long chainlong chain entanglements, particularly for the $C_{\mathrm{L}} \leq \mathrm{C}_{\mathrm{L}}{ }^{*}$ blends where the strong nonlinear effects of concentration on $\sigma_{\text {skin }}$ are observed. This is in contrast to studies where the formation of oriented structures is attributed to the increase in orientation or stretch caused by entanglements between the longest chains in the melt. ${ }^{[33}$ 47, 49, 63] In our bimodal blends, no significant degree of long chain-long chain entanglement is expected even for the highest $C_{\mathrm{L}}$. Furthermore, once the long chains pervade the entire volume $\left(C_{\mathrm{L}} \geq C_{\mathrm{L}}{ }^{*}\right)$, the concentration effect on $\sigma_{\text {skin }}$ becomes weaker - not stronger - for both $M_{\mathrm{L}}=$ $1 \mathrm{M} \mathrm{g} / \mathrm{mol}^{[27,54]}$ and $3.5 \mathrm{M} \mathrm{g} / \mathrm{mol}$ (e.g., $\sigma_{\text {skin }}$ varies weakly with increasing concentration beyond $C_{\mathrm{L}} \approx \mathrm{C}_{\mathrm{L}}{ }^{*}$, Figure 8 bottom). Within the context of our model, the saturation as $C_{\mathrm{L}}$ increases suggests that point-like precursors may have a limited capacity to adsorb long chains, which becomes saturated when long chains pervade the entire volume.

Time for Birefringence Upturn. During shear at sufficiently high stresses $\sigma \geq \sigma_{\text {skin' }}$ the prolific formation of shish (and some kebabs) ${ }^{[6]}$ can produce a sharp increase in birefringence. Thus, the "birefringence upturn time" $t_{\mathrm{u}}$ provides a measure of the time elapsed from inception of shear to prolific initiation of threads from which a highly oriented skin develops. Recent experimental results suggest that the time lag between inception of shear and prolific formation of shish may be mainly attributed to the time required to form flow-induced point-like precursors. For instance, Janeschitz-Kriegl and co-workers observed a steady increase in the number of point-like nuclei up to $10^{16} \mathrm{~m}^{-3}$ with increasing specific work and formation of shish at higher values of work. ${ }^{[28]}$ Also, Housmans et al. deduced an increase in the number of point-nuclei with increasing shearing time up to a saturation value of $10^{14} \mathrm{~m}^{-3}$ before the emergence of shish. [32] In view of this, the reduction of the upturn time as $C_{\mathrm{L}}$ is increased (but still below $C_{\mathrm{L}}{ }^{*}$ ) for the $3.5 \mathrm{M}$ blends suggests that the addition of a few $3.5 \mathrm{M}$ chains perceptibly enhances the rate of formation of point-like precursors. Some evidence of this can be seen in Figure 6 middle: addition of just $0.6 C_{\mathrm{L}}$ * (i.e., $0.25 \%$ ) of $3.5 \mathrm{M}$ long chains leads to a fine-grained layer $\sim 100 \mu \mathrm{m}$ thick (where $\sigma>0.4 \mathrm{MPa}$ ) in which spherulites are much smaller than the corresponding region in $\mathrm{B} 0$. If the upturn time is governed by the lag time for formation of pointlike precursors, the insensitivity of $t_{\mathrm{u}}$ when $C_{\mathrm{L}}>C_{\mathrm{L}}{ }^{*}$ may indicate a saturation of the effect of $3.5 \mathrm{M}$ chains on formation of point-like precursors.

In contrast to the $3.5 \mathrm{M}$ long chains, the addition of $1 \mathrm{M}$ long chains did not noticeably enhance the formation of pointlike precursors in the same matrix polymer: the upturn time did not decrease and the spherulite size did not perceptibly change. ${ }^{[27]}$ If point-like precursors are envisioned to form from isolated ordering events in the melt, the ability of long chains to undergo chain stretching $\left(\tau_{R L}>\tau_{S}\right)$ should play a role. As noted earlier, $1 \mathrm{M}$ chains in a 186K matrix do not satisfy this criterion $\left(\tau_{R, 1 \mathrm{M}}<\tau_{\mathrm{S}}\right)$ chains, while $3.5 \mathrm{M}$ chains in the same matrix do have $\tau_{R, 3.5 \mathrm{M}}>\tau_{\mathrm{S}}$ (Figure 12, i.e., isolated untethered $3.5 \mathrm{M}$ chains can undergo chain stretching in the melt).

\section{Conclusion}

All long chains are not created equal. When placed into an identical matrix having molar mass $M_{\mathrm{S}} \approx 27 M_{\mathrm{e}^{\prime}}$ a small concentration of chains having length $M_{\mathrm{L}} / M_{\mathrm{S}} \approx 20$ can have dramatically stronger effects than long chains with $M_{\mathrm{L}} / M_{\mathrm{S}}$ $\approx 5$. At less than $0.2 \%$ by mass, long chains with $M_{\mathrm{L}} / M_{\mathrm{S}} \approx$ 20 reduce the threshold stress for prolific shish formation by more than $30 \%$ - an effect that cannot be achieved with $M_{L} /$ $M_{\mathrm{S}} \approx 5$ even at the highest concentration examined (>1.5\%). In addition, long chains of $M_{\mathrm{L}} / M_{\mathrm{S}} \approx 20$ have two effects that were not observed with $M_{\mathrm{L}} / M_{\mathrm{S}} \approx 5$ : these very long chains enhance flow-induced formation of point-like precursors and flow-induced formation of "sausages". As suggested by Van Meerveld et al., these differences may relate to the extent of chain stretching of the long chains during shear. [45] Specifically, strong effects are observed for long chains whose Rouse time (required for chain length equilibration) is greater than the reptation time of the matrix chains $\left(\tau_{R, L}\right.$ $>\tau_{D, S}$. Note that this criterion depends not only on the ratio of chain lengths, $M_{\mathrm{L}} / M_{\mathrm{S}}$, but also on the degree of entanglement of the matrix, $M_{\mathrm{S}} / M_{\mathrm{e}}$ : the condition $\tau_{\mathrm{R}, \mathrm{L}}>\tau_{\mathrm{D}, \mathrm{S}}$ is satisfied when $\left(M_{\mathrm{L}} / M_{\mathrm{S}}\right)^{2}>3 M_{\mathrm{S}} / M_{\mathrm{e}}$. The more entangled the matrix, the greater the relative length of the long chains compared to the matrix chains must be to produce a dramatic enhancement in flow-induced crystallization.

By producing such strong effects on $\sigma_{\text {skin }}$ (Figure 8), long chains with $M_{\mathrm{L}} / M_{\mathrm{S}} \approx 20$ unambiguously confirm three tentative conclusions based on $M_{\mathrm{L}} / M_{\mathrm{S}} \approx 5$. First, the mechanism by which long chains enhance shish formation is clearly cooperative: if it were a single chain effect, the threshold stress would not change with increasing $C_{\mathrm{L}}$-for a particular shortterm shear protocol, only the number of precursors formed would change and merely in proportion to $C_{\mathrm{L}}$. Second, addition of long chains can enable prolific creation of threadlike precursors even at concentrations well below $C_{\mathrm{L}}{ }^{*}$. Third, the effect of further addition of long chains levels off above $C_{\mathrm{L}}{ }^{*}$, indicating that the supply of long chains in formation of shish is no longer a limiting factor.

Also, there appear to be two stages - inititation and propagation - in thread formation from an already present pointlike nucleus, with initiation having a more stringent stress requirement than that required for propagation of the thread 
$\left(\sigma_{\text {init }}>\sigma_{\text {prop }}\right)$. Thus, if an infrequent event-such as a locally higher stress in the vicinity of a dust particle or catalyst fragment-causes an initiation event at a lower stress than the critical stress for the skin, the thread may propagate for tens of micrometers if $\sigma>\sigma_{\text {prop. }}$. This may explain the observation of relatively long and isolated sausage-type structures in optical micrographs of this and other studies. $[1,25,27]$

In hindsight, prior experiments using long chains of $1 \mathrm{M}$ $\mathrm{g} / \mathrm{mol}\left(M_{\mathrm{L}} / M_{\mathrm{S}} \approx 5\right)$ are now seen to be a marginal case: only when tethered near their ends would the $1 \mathrm{M}$ long chains experience chain stretching. By moving to significantly longer chains, it becomes possible for 3.5M chains adsorbed anywhere along their length to develop a strongly oriented portion near the adsorption site. Indeed, we believe this produces a dramatic increase in proliferation of shish. The data are consistent with the hypothesis that the interaction of long chains with the tip of a shish creates a local orientation that is not found elsewhere in the flowing melt. The results anticipate that a molecular perspective on chain dynamics both in the melt and when adsorbed to precursors may provide predictive models linking molecular weight distributions and flow conditions with the resulting kinetics and morphology of crystallization. In relation to the concept of a critical molecular weight $M_{\mathrm{L}} *[38,64]$ the present results caution against lumping all $M_{\mathrm{L}}>M_{\mathrm{L}}{ }^{*}$ together. As chain length increases beyond the marginal length, qualitative changes in their effects occur, underscoring the importance of studies with model materials: even subtle differences in the distribution of the longest chains can have a considerable impact on the type of morphology that forms.

Physical insight into the molecular processes that determine whether a highly oriented skin or a "sausage" layer forms is important because the final properties in the solid state depend on the morphology. It is well-known that optical, thermal, transport, and mechanical properties all depend strongly on the level of orientation. Therefore, we offer a conceptual model that captures the occurrence of both "sausage" regions and the highly oriented skin. The mechanisms are speculative, as they cannot be observed directly. Nevertheless, they may provide the underpinnings of theoretical models with testable predictions regarding the dependence of the threshold stresses, propagation velocity, and upturn time that can be subjected to experimental validation.

Acknowledgment - The authors thank Dr. Robert Sammler of Dow Chemical Company for kindly providing the matrix iPP materials used in this study. They are also grateful to Dr. Igors Sics and Dr. Lixia Rong of beamline X27C (NSLS) for assistance in X-ray experiments. The ITP workshop is acknowledged, including discussions with Tom McLeish and Scott Milner. Funding was provided by the National Science Foundation under Grant DMR-0505393.

\section{Notes}

a. Point-like nuclei do not necessarily have a point-like geometry. We agree with Janeschitz-Kriegl's view, ${ }^{[30]}$ which considers that all flow-induced precursors are long and slender. The spherulitic morphology that arises from the so-called point-like nuclei is simply a consequence of the large distance between those precursors relative to their length. Figure 10a of ref 31 shows a transmission electron micrograph in which a spherulitic structure has emerged due to "point-like" precursors of short length compared to the distance between them. b. In pressure-driven flow through a slit, the shear stress varies linearly from $\sigma_{\mathrm{w}}$ at the wall to zero at the center (Figure 1). Thus, the shear stress corresponding to the boundary between different morphologies is proportional to the distance from the center of the channel.

c. It should be noted that the sausage-like structures may be embedded within a fine-grained layer but that the presence of the former may hinder the observation of the latter. Blends containing $\geq 0.5 \mathrm{wt} \%$ of long chains $\left(C_{\mathrm{L}} / C_{\mathrm{L}}{ }^{*} \geq 1.2\right)$ generally had a thick sausage layer without a clear fine-grained layer, so only $\sigma_{\text {saus }}$ is reported.

d. This rate is estimated from the TEM of Seki and co-workers ${ }^{[27]}$ where the sample B1 is sheared for $t_{\mathrm{s}}=1.4 \mathrm{~s}$ and exhibits shish longer than $20 \mu \mathrm{m}$ (field of view).

e. The observed distance between point nuclei in fine grained layers is on the order of $\sim 10 \mu \mathrm{m}$ after shearing for more than $1 \mathrm{~s}$ at 0.11 MPa (Figure 5). Janeschitz-Kriegl et al.[28] found an upper bound of $10^{16}$ point nuclei $/ \mathrm{m}^{3}$ at the transition to shish formation, consistent with $\sim 10 \mu \mathrm{m}$ of point-nuclei interdistance. An even lower point-nuclei density of $\sim 10^{14} / \mathrm{m}^{3}$ was calculated by Housmans et al. ${ }^{[32]}$ corresponding to a larger point-nuclei interdistance. Kumaraswamy et al. ${ }^{[57]}$ observed spherulitic structures which were several micrometers in size in the fine-grained layer near the boundary with highly oriented skin.

$\mathrm{f}$. The radius of gyration $R_{\mathrm{g}}$ for base-PP, $1 \mathrm{M}$ chains, and $3.5 \mathrm{M}$ chains are estimated to be $\sim 17,39$, and $73 \mathrm{~nm}$ from $R_{\mathrm{g}} /\left(M_{\mathrm{w}}{ }^{0.5}\right)=0.39 \AA /$ $(\mathrm{g} / \mathrm{mol})^{1 / 2} \cdot[52]$

g. Seki et al. ${ }^{[27]}$ observed thread lengths of at least $20 \mu \mathrm{m}$ (limited by the image field of view) for their $1 \mathrm{M} \mathrm{g} / \mathrm{mol}$ blends. Since the Rouse time of $1 \mathrm{M}$ long chains is faster than the short chain disengagement time (Figure 12), 1M chains are not expected to stretch when free in the melt and are a borderline case if they become adsorbed onto a point nuclei, so that not a significant amount of stretch is foreseeable. Thus, we can make a generous upper bound estimation of the extent of reach of a single $1 \mathrm{M}$ chain by estimating the size of an entanglement blob $(\sim 2.5 \mathrm{~nm})$ and computing the length of the chain if all blobs were laid out in a line, i.e., $\sim 0.5 \mu \mathrm{m}$. Therefore, a long chain must attach to the initial point nucleus to initiate the thread and, after initiation, successive attachments of long chains must occur to propagate the thread to greater lengths. It is highly unlikely for the long chains to attain a fully extended conformation under our shear conditions, but as an upper bound the maximum end-to-end length of $1 \mathrm{M} / \mathrm{mol}$ chains is estimated as $R_{\max }=\mathrm{Nb} \sim 7 \mu \mathrm{m}$. For our $3500 \mathrm{~kg} / \mathrm{mol}$ long chains, we observe that some sausage structures can attain lengths over $100 \mu \mathrm{m}$ (Figure 14), so the central thread in those sausages even exceeds the fully extended reach of a long chain $R_{\max }=\mathrm{Nb} \sim 24 \mu \mathrm{m}$.

\section{References}

[1] Liedauer, S.; Eder, G.; Janeschitzkriegl, H.; Jerschow, P.; Geymayer, W.; Ingolic, E. Int. Polym. Process. 1993, 8 (3), 236-244.

[2] Kumaraswamy, G.; Verma, R. K.; Kornfield, J. A. Rev. Sci. Instrum. 1999, 70 (4), 2097-2104.

[3] Langouche, F. Macromolecules 2006, 39 (7), 2568-2573.

[4] Mykhaylyk, O. O.; Chambon, P.; Graham, R. S.; Fairclough, J. P. A.; Olmsted, P. D.; Ryan, A. J. Macromolecules 2008, 41 (6), 1901- 1904.

[5] Cavallo, D.; Azzurri, F.; Balzano, L.; Funari, S. S.; Alfonso, G. C. Macromolecules 2010, 43 (22), 9394-9400.

[6] Fernandez-Ballester, L.; Thurman, D. W.; Kornfield, J. A. J. Rheol. 2009, 53 (5), 1229-1254.

[7] Fernandez-Ballester, L.; Gough, T.; Meneau, F.; Bras, W.; Ania, F.; Francisco, J. C.; Kornfield, J. A. J. Synchrotron Radiat. 2008, $15,185-190$. 
[8] Brintzinger, H. H.; Fischer, D.; Mulhaupt, R.; Rieger, B.; Waymouth, R. M. Angew. Chem., Int. Ed. Engl. 1995, 34 (11), 1143- 1170.

[9] Coates, G. W. Chem. Rev. 2000, 100 (4), 1223-1252.

[10] Johnson, L. K.; Killian, C. M.; Brookhart, M. J. Am. Chem. Soc. 1995, 117 (23), 6414-6415.

[11] Koutalas, G.; Iatrou, H.; Lohse, D. J.; Hadjichristidis, N. Macromolecules 2005, 38 (12), 4996-5001.

[12] Fernyhough, C. M.; Young, R. N.; Poche, D.; Degroot, A. W.; Bosscher, F. Macromolecules 2001, 34 (20), 7034-7041.

[13] Kumaraswamy, G.; Kornfield, J. A.; Yeh, F. J.; Hsiao, B. S. Macromolecules 2002, 35 (5), 1762-1769.

[14] Kimata, S.; Sakurai, T.; Nozue, Y.; Kasahara, T.; Yamaguchi, N.; Karino, T.; Shibayama, M.; Kornfield, J. A. Science 2007, 316 (5827), 1014-1017.

[15] Balzano, L.; Kukalyekar, N.; Rastogi, S.; Peters, G. W. M.; Chadwick, J. C. Phys. Rev. Lett. 2008, 1 (4), xxxx.

[16] Janeschitz-Kriegl, H.; Ratajski, E.; Wippel, H. Colloid Polym. Sci. 1999, 277 (2-3), 217-226.

[17] Andersen, P. G.; Carr, S. H. Polym. Eng. Sci. 1978, 18 (3), 215- 221.

[18] Haas, T. W.; Maxwell, B. Polym. Eng. Sci. 1969, 9 (4), 225-\&.

[19] Fujiyama, M.; Wakino, T.; Kawasaki, Y. J. Appl. Polym. Sci. 1988, 35 (1), 29-49.

[20] Kantz, M. R.; Stigale, F. H.; Newman, H. D. J. Appl. Polym. Sci. 1972, 16 (5), 1249-\&.

[21] Trotignon, J. P.; Verdu, J. J. Appl. Polym. Sci. 1987, 34 (1), 1- 18.

[22] Liedauer, S.; Eder, G.; Janeschitzkriegl, H. Int. Polym. Process. 1995, 10 (3), 243-250.

[23] Flory, P. J. J. Chem. Phys. 1947, 15 (6), 397-408.

[24] Hill, M. J.; Keller, A. J. Macromol. Sci., Phys. 1969, B 3 (1), $153-\&$.

[25] Kumaraswamy, G.; Issaian, A. M.; Kornfield, J. A. Macromolecules 1999, 32 (22), 7537-7547.

[26] Balzano, L.; Rastogi, S.; Peters, G. Macromolecules 2011, 44 (8), 2926-2933.

[27] Seki, M.; Thurman, D. W.; Oberhauser, J. P.; Kornfield, J. A. Macromolecules 2002, 35 (7), 2583-2594.

[28] Janeschitz-Kriegl, H.; Ratajski, E.; Stadlbauer, M. Rheol. Acta 2003, 42 (4), 355-364.

[29] Balzano, L.; Cavallo, D.; Erp, T. B. V.; Ma, Z.; Housmans, J.W.; Fernandez-Ballester, L.; Peters, G. W. M. IOP Conf. Ser.: Mater. Sci. Eng. 2010, 14 (1), 012005.

[30] Janeschitz-Kriegl, H.; Ratajski, E. Colloid Polym. Sci. 2010, 288 (16-17), 1525-1537.

[31] Kornfield, J. A.; Kumaraswamy, G.; Issaian, A. M. Ind. Eng. Chem. Res. 2002, 41 (25), 6383-6392.

[32] Housmans, J. W.; Steenbakkers, R. J. A.; Roozemond, P. C.; Peters, G. W. M.; Meijer, H. E. H. Macromolecules 2009, 42 (15), 5728-5740.

[33] Ogino, Y.; Fukushima, H.; Matsuba, G.; Takahashi, N.; Nishida, K.; Kanaya, T. Polymer 2006, 47 (15), 5669-5677.

[34] Zhang, C.; Hu, H.; Wang, D.; Yan, S.; Han, C. C. Polymer 2005, 46 (19), 8157-8161.

[35] Sherwood, C. H.; Price, F. P.; Stein, R. S. J. Polym. Sci., Part C: Polym. Symp. 1977, 63, 77-94.

[36] Jerschow, P.; JaneschitzKriegl, H. Int. Polym. Process. 1997, 12 (1), 72-77.

[37] Vleeshouwers, S.; Meijer, H. E. H. Rheol. Acta 1996, 35 (5), 391-399.
[38] Nogales, A.; Hsiao, B. S.; Somani, R. H.; Srinivas, S.; Tsou, A. H.; Balta-Calleja, F. J.; Ezquerra, T. A. Polymer 2001, 42 (12), 5247- 5256.

[39] Somani, R. H.; Yang, L.; Hsiao, B. S. Polymer 2006, 47 (15), 5657-5668.

[40] Lagasse, R. R.; Maxwell, B. Polym. Eng. Sci. 1976, 16 (3), 189- 199.

[41] Keller, A.; Kolnaar, H. W. H. Flow-Induced Orientation and Structure Formation. In Processing of Polymers; Meijer, H. E. H., Ed.; Wiley-VCH: New York, 1997; Vol. 18, pp 189-268.

[42] Duplay, C.; Monasse, B.; Haudin, J. M.; Costa, J. L. J. Mater. Sci. 2000, 35 (24), 6093-6103.

[43] Graham, R. S.; Olmsted, P. D. Phys. Rev. Lett. 2009, 103 (11), 4.

[44] Steenbakkers, R. J. A.; Peters, G. W. M. J. Rheol. 2011, 55 (2), 401-433.

[45] van Meerveld, J.; Peters, G. W. M.; Hutter, M. Rheol. Acta 2004, 44 (2), 119-134.

[46] Yang, L.; Somani, R. H.; Sics, I.; Hsiao, B. S.; Kolb, R.; Fruitwala, H.; Ong, C. Macromolecules 2004, 37 (13), 4845-4859.

[47] Keum, J. K.; Zuo, F.; Hsiao, B. S. Macromolecules 2008, 41 (13), 4766-4776.

[48] Heeley, E. L.; Fernyhough, C. M.; Graham, R. S.; Olmsted, P. D.; Inkson, N. J.; Embery, J.; Groves, D. J.; McLeish, T. C. B.; Morgovan, A. C.; Meneau, F.; Bras, W.; Ryan, A. J. Macromolecules 2006, 39 (15), 5058-5071.

[49] Matsuba, G.; Sakamoto, S.; Ogino, Y.; Nishida, K.; Kanaya, T. Macromolecules 2007, 40 (20), 7270-7275.

[50] Doufas, A. K.; Dairanieh, I. S.; McHugh, A. J. J. Rheol. 1999, 43 (1), 85-109.

[51] Janeschitz-Kriegel, H.; Ratajski, E. Polymer 2005, 46 (11), 3856-3870.

[52] Ballard, D. G. H.; Cheshire, P.; Longman, G. W.; Schelten, J. Polymer 1978, 19 (4), 379-385.

[53] Hongladarom, K.; Burghardt, W. R.; Baek, S. G.; Cementwala, S.; Magda, J. J. Macromolecules 1993, 26 (4), 772-784.

[54] Thurman, D. W. Molecular Aspects of Flow-Induced Crystallization of Polypropylene; California Institute of Technology: Pasadena, CA, 2005.

[55] Kumaraswamy, G.; Verma, R. K.; Kornfield, J. A.; Yeh, F. J.; Hsiao, B. S. Macromolecules 2004, 37 (24), 9005-9017.

[56] Doi, M.; Edwards, S. F. The Theory of Polymer Dynamics; Oxford University Press: New York, 1986.

[57] Kumaraswamy, G.; Verma, R. K.; Issaian, A. M.; Wang, P.; Kornfield, J. A.; Yeh, F.; Hsiao, B. S.; Olley, R. H. Polymer 2000, 41 (25), 8931-8940.

[58] White, H. M.; Bassett, D. C. Polymer 1997, 38 (22), 5515- 5520.

[59] Baert, J.; Van Puyvelde, P.; Langouche, F. Macromolecules 2006, 39 (26), 9215-9222.

[60] Janimak, J. J.; Cheng, S. Z. D.; Giusti, P. A.; Hsieh, E. T. Macromolecules 1991, 24 (9), 2253-2260.

[61] Eder, G.; Janeschitzkriegl, H.; Liedauer, S. Prog. Polym. Sci. 1990, 15 (4), 629-714.

[62] Wang, M.; Hu, W.; Ma, Y.; Ma, Y.-q. Macromolecules 2005, 38 (7), 2806-2812.

[63] Yan, T. Z.; Zhao, B. J.; Cong, Y. H.; Fang, Y. Y.; Cheng, S. W.; Li, L. B.; Pan, G. Q.; Wang, Z. J.; Li, X. H.; Bian, F. G. Macromolecules 2010, 43 (2), 602-605.

[64] Somani, R. H.; Hsiao, B. S.; Nogales, A.; Srinivas, S.; Tsou, A. H.; Sics, I.; Balta-Calleja, F. J.; Ezquerra, T. A. Macromolecules 2000, 33 (25), 9385-9394. 